\title{
1 Understanding the rise of cardiometabolic diseases in low- and 2 middle-income countries
}

4 J. Jaime Miranda $(1,2)$

5 Tonatiuh Barrientos-Gutiérrez (3)

6 Camila Corvalan (4)

7 Adnan A. Hyder (5)

8 Maria Lazo-Porras $(1,6)$

9 Tolu Oni $(7,8)$

10 Jonathan C. K. Wells (9)

1. CRONICAS Center of Excellence in Chronic Diseases, Universidad Peruana Cayetano Heredia, Lima, Peru

2. School of Medicine, Universidad Peruana Cayetano Heredia, Lima, Peru

3. Center for Population Health Research, National Institute of Public Health, Cuernavaca, Mexico

4. Unit of Public Health, Institute of Nutrition and Food Technology, University of Chile, Santiago, Chile

5. Milken Institute School of Public Health, George Washington University, Washington, DC, USA

6. Division of Tropical and Humanitarian Medicine, University of Geneva, Geneva, Switzerland

7. MRC Epidemiology Unit, University of Cambridge, Cambridge, UK

8. Research Initiative for Cities Health and Equity (RICHE), Division of Public Health Medicine, School of Public Health and Family Medicine, University of Cape Town, South Africa

9. Childhood Nutrition Research Centre, UCL Great Ormond Street Institute of Child Health, London, UK

Corresponding author

Dr. J. Jaime Miranda, MD, PhD

Address: CRONICAS Center of Excellence in Chronic Diseases, Universidad Peruana

33 Cayetano Heredia, Av Armendariz 495, Miraflores, Lima 18, Peru

34 Telephone: $+51-1-241-6978$

35 E-mail: Jaime.Miranda@upch.pe 


\section{Abstract}

37 Increases in the prevalence of non-communicable diseases (NCDs), but in particular 38 cardiometabolic diseases such as cardiovascular disease, stroke and diabetes, and their 39 major risk factors, have not been uniform across settings; for example, cardiovascular 40 disease mortality has declined over recent decades in high-income countries but increased 41 in low- and middle-income countries (LMICs). The factors contributing to this rise are varied 42 and are contributed to by the environmental, social, political and commercial determinants of 43 health, among other factors. This Review focuses on understanding the rise of 44 cardiometabolic diseases in LMICs, with particular emphasis on obesity and its drivers, 45 together with broader environmental and macro determinants of health, and the LMIC-based 46 responses to counteract cardiometabolic diseases. 


\section{Introduction}

48 In the academic and political community, non-communicable diseases (NCDs) have been 49 framed as a global emergency. ${ }^{1,2}$ The economic burden that non-communicable diseases 50 (NCDs) impose to low- and middle-income countries (LMICs) has contributed to the visibility 51 of NCDs within the broader global health policy environment, ${ }^{3}$ and the projected economic 52 losses worldwide by 2030 associated with NCDs have been calculated to be $\$ 47$ trillion. ${ }^{4,5}$ 53 Furthermore, health is considered one of the key Sustainable Development Goals (SDGs) 54 proposed by the UN (Box 1).

55 NCDs involve a variety of conditions including cardiovascular and pulmonary disease, 56 diabetes and cancer; our focus here is on those considered cardiometabolic NCDs 57 cardiovascular disease, stroke and diabetes. In high-income countries (HICs), such NCDs 58 are heavily clustered among people with low socioeconomic status, and NCDs are an 59 important cause of medical impoverishment. ${ }^{6-9}$ However, the highest chances of dying from 60 NCDs are observed in low-income and middle-income countries (LMICs), ${ }^{6,10}$ and in these 61 countries, while they remain most common among wealthier groups, the fastest rates of 62 increase are again among poorer socio-economic groups. ${ }^{11}$

63 Changes in the prevalence of cardiometabolic diseases and their major risk factors have not 64 been uniform across settings. Over recent decades, cardiovascular disease mortality has 65 declined in $\mathrm{HICs}^{12-16}$ and increased in LMICs, ${ }^{12,13}$ and diabetes prevalence has increased 66 worldwide but at a faster rate in LMICs. ${ }^{17,18}$ Moreover, NCD mortality occurs on average at 67 earlier ages in LMICs, and the increasing number of years spent living with such conditions, 68 their complications and multimorbidities, have major consequences at individual, community, 69 societal and country levels.

70 Cardiometabolic diseases are linked to several risk factors, namely obesity, hypertension, 71 diet, tobacco, air pollution and physical inactivity. ${ }^{19,20}$ Hypertension and low education are 72 key contributors to cardiovascular events and mortality worldwide, yet the contribution of 73 other risks, e.g. household air pollution and poor diet, vary by a country's economic level. ${ }^{21}$ 74 Despite the overall risk-factor burden appearing lower in LMICs relative to $\mathrm{HICs},{ }^{22}$ rates of 75 major cardiovascular events such as death from cardiovascular causes, myocardial 76 infarction, stroke, or heart failure, are lower in HICs than in LMICs, an observation that could 77 reflect poor management and weak health systems infrastructure. ${ }^{22}$ Many of the 78 achievements in NCD control in HICs are closely related to better healthcare delivery and management of risk factors ${ }^{12}$ 
The epidemiology and management of NCDs in LMICs have received detailed attention, ${ }^{10,11,23}$ and roadmaps to address specific diseases have been devised. ${ }^{24}$ Hence, rather than focusing on the epidemiology and treatment of these diseases and their risk factors, in this Review we aim to provide a broader and more nuanced understanding of why the epidemic of cardiometabolic NCD has exploded in LMIC settings. We address this by focusing on the complex exposures faced by individuals raised in LMICs, in particular as their environments become more toxic and obesogenic. In this Review we also explore the commercial determinants of health, particularly in urban populations, together with population-wide responses arising from LMIC settings. As an overarching conceptual approach, we draw on the 'capacity-load' model of NCD (Figure 1). ${ }^{25,26}$ Below, we consider how the epidemiology of NCDs in LMICs is shaped by the particular exposure of individuals in these countries to factors affecting both metabolic capacity and load.

The social and environmental determinants of cardiometabolic 93 disease in LMICs

\section{Nutrition}

The rise of cardiometabolic diseases has been strongly linked to rises in obesity. For example in Africa, a study found that the age-standardized mean body mass index (BMI) increased from 21.9 to 24.9 in women and from 21 to 23 in men, and a positive association was observed between diabetes prevalence and BMI in 1980 and $2014 .{ }^{27}$ Globally, much of the increases in BMI has recently been linked to a predominant rise of BMI in rural areas. ${ }^{28}$ Between 1975 and 2016, the global prevalence of obesity increased from $3 \%$ to $11 \%$ among men and from $6 \%$ to $15 \%$ among women, ${ }^{29}$ with different patterns of change across different world regions. The rise in obesity varies between countries in association with socioeconomic status and gender. ${ }^{30}$ It is notable that the increase in obesity is not just focused on adults, but has also increased in children and adolescents worldwide, from below $1 \%$ in 1975 to $6-8 \%$ in $2016 .{ }^{29}$ Results from a Norwegian longitudinal studies with an average follow-up of 45 years showed that obesogenic environments are major contributors to the epidemics of obesity and NCDs and contribute more than genetic predisposition. ${ }^{31}$ This suggests that the environment is the primary determinant of the metabolic load (Figure 1) that humans accommodate to in their daily lives, particularly in terms of food and physical activity.

Much of the rise in the burden of cardiometabolic conditions in LMICs is closely linked to the recent epidemiological transition observed in these countries, that is the change in the pattern of causes of mortality from a predominance of infectious disease to NCDs, ${ }^{32-34}$ a 
114 change that is occurring in the context of persisting or recent under-nutrition. ${ }^{25,35}$ It is notable,

115 however, that the obesogenic environment might also influence different populations

116 differently with respect to disease development. For example, Asian populations develop

117 diabetes at relatively low levels of BMI. ${ }^{23,36,37}$ The capacity-load model (Figure 1) suggests

118 that exposures in early life such as a large burden of infections and chronic undernutrition

119 that were experienced decades ago by today's adults in LMICs still has negative effects on

120 their health. ${ }^{38-41}$ Importantly, with respect to the present day, in the 1970s-1980s more than

$12150 \%$ of the population in LMICs were stunted ${ }^{42}$, thus introducing in these populations long-

122 term deficits in metabolic capacity. ${ }^{43}$ Adults in LMICs tend to experience cardiovascular and

123 metabolic conditions much earlier in their adulthood than those born and raised in HICs,

124 which may be due to such different population penalties from hardship earlier in life..$^{44,45}$

125 Whilst undernutrition has not disappeared in LMICs, over the last four decades we have 126 observed a rise in BMl in children and adolescents worldwide. ${ }^{29}$ Within one or two 127 generations, as in the cases of Mexico ${ }^{46}$ and Chile, ${ }^{47}$ this transition has resulted in what is 128 known as the "double burden of malnutrition" at the individual, household and community 129 level. ${ }^{48,49}$ Children exposed to the double burden will not develop to reach their full potential 130 when transitioning into adulthood, ${ }^{40,50-52}$ and it is likely that today's children in LMICs will also 131 have higher exposures, to ever more common obesogenic environments, at higher doses 132 and for longer durations than in the past.

133 Much of the world's rise in BMI and thus, increases in obesity, has recently been attributed 134 to changes in BMI in rural settings, ${ }^{28}$ and understanding the contribution of the rural and 135 urban environments to obesity is important. When compared to those exposed to rural or 136 urban environments only, migrants serve as tracers of how exposure to different 137 environments affect cardiometabolic adaptations and responses. ${ }^{53}$ For example, in the 138 PERU MIGRANT study, it was observed that among rural-to-urban migrants, those who 139 migrated when aged older than 12 years had higher probability of developing diabetes, 140 impaired fasting glucose and metabolic syndrome compared to people who migrated at 141 younger ages. ${ }^{54}$ These observations indicate different reactions to the exposure to urban 142 environments depending on age, with those migrating at younger ages having greater 143 plasticity to adapt to their new environments.

\section{The nutrition environment}

145 Sustainable food systems are essential to achieve the SDGs. ${ }^{55}$ Economic improvement, 146 trade liberalization and increasing urbanization have resulted in important changes in the 
147 LMIC food environment, defined as the composition, promotion, availability, accessibility and 148 affordability of foods. ${ }^{56}$

149 In recent years, LMIC settings have experienced an increased availability of foods produced 150 by large international food corporations, as well as an important expansion of supermarkets 151 and fast-food chains which in part is driven by the Commercial Determinants of Health (see 152 below). ${ }^{57,58}$ As a result, people living in urban areas have rapid and cheap access to more 153 packaged, ready to eat or ready to heat foods manufactured by multinational food 154 corporations, compared to local foods that could be obtained in traditional open air markets, 155 such as fruits, vegetables, and cereals. ${ }^{59,60}$ In the case of children, this scenario is worsened 156 by the presence of street-vendors in the surroundings of daycares and schools who now 157 offer snacks and industrialized beverages to children instead of natural foods, as shown in 158 examples from Brazil, Guatemala and Mexico. ${ }^{61-63}$ Compounding this, an important 159 proportion of children do not have access to clean water during long periods in the day, and 160 some prefer to offer them sugar sweetened beverages. ${ }^{64}$ Similarly, over the past two 161 decades, away-from-home food intake has had a large increase, with for example fast-food chains now spread all over the Latin American continent. ${ }^{57}$

163 The increased availability of packaged and ready-to-eat foods is worrisome because these 164 foods tend to be higher in nutrients of concern such as added sugars, sodium, saturated fat, 165 and trans fat compared to unpackaged foods, whilst also being deficient in key 166 micronutrients. ${ }^{65-68}$ Moreover, recent evidence indicates that the nutrient composition of 167 packaged food products varies importantly around the world, being considerably less healthy 168 in LMICs such as Chile and Mexico. ${ }^{69}$ No age group is unexposed to these dietary trends, 169 and even infants are at risk of receiving energy-dense micronutrient-poor complementary 170 foods. $^{70}$

171 Importantly, food prices have also evolved in recent years in LMICs. Large-scale sells have 172 allowed lower prices for packaged food products, so that it is now relatively cheaper to buy 173 foods high in sugar, fat, and sodium such as sugary sodas or salty snacks than healthy 174 foods such as fruits, vegetables, and dairy products; although this association may vary 175 depending on the income and development level of the country. ${ }^{71}$ The result is that these 176 products have become accessible to, and marketed at, the poorer socio-economic groups. 177 The consumption of ultra-processed foods has increased, for example throughout the Latin 178 American and Caribbean region, while consumption of healthy foods has remained low. ${ }^{72}$ 179 Consumption of ultra-processed foods is a key factor driving the epidemic of NCDs currently 180 imposing the greatest health and economic burden in LMICs, such as diabetes, 181 cardiovascular disease, and some types of cancer. ${ }^{59,73-75}$ 
182 It is important to note that the penetration of ultra-processed foods have also reached rural 183 settings, in which women increasingly work more in non-farm occupations, which in turn 184 increases the demand for convenience food. ${ }^{57,76}$ Supermarkets initially opened in large cities 185 but have progressively expanded to small towns in rural areas through convenience stores 186 and small supermarkets. Marketing strategies of unhealthy food products have also spread 187 into rural areas. Therefore, not surprisingly, recent reports indicate that is precisely in rural 188 areas where obesity is increasing faster in LMICs. ${ }^{28}$

\section{Air pollution}

190 Another key source of metabolic load in LMICs is air pollution. This contributes to adult 191 morbidity and mortality through chronic obstructive pulmonary disease (COPD), stroke and 192 ischaemic heart disease, but also affects young children through acute lower respiratory 193 infections, ${ }^{77}$ thus undermining metabolic capacity in early life (Figure 1). Already, air 194 pollution is suggested to account for $19 \%$ of all cardiovascular deaths and $21 \%$ of all stroke 195 deaths globally, ${ }^{78}$ and $87 \%$ of this burden occurs in LMICs, concentrated in particular in sub196 Saharan Africa and south and east Asia ${ }^{79}$ (Box 2).

197 Burning biomass for household fuel has long been a key source of air pollution in LMICs, ${ }^{80,81}$ 198 and more recently there has been rapid increases in the volume of vehicle traffic in many 199 cities which are an additional burden on human health and in urban areas where road 200 vehicle emissions are further concentrated. ${ }^{82-85}$ As reported by the International Energy 201 Agency, transport accounted for one quarter of total global CO2 emissions in 2016, a level $20271 \%$ higher than in $1990 .^{86}$ The highest absolute increase was in road transport, and while 203 theAmericas historically had the highest transport emission levels of all regions, and this has 204 continued over recent years, Asia is quickly closing the gap with annual growth rates in 205 emissions five times larger than the Americas. ${ }^{86}$ Importantly, urban planning in LMICs has 206 lagged behind the rapidly rising traffic volumes, ${ }^{87,88}$ and the typical vehicles in LMICs are 207 more polluting than those in HICs. ${ }^{77,89}$.

208 There is increasing recognition that air pollution damages almost every organ in the body, 209 and is for example linked with heart disease, dementia and diabetes morbidity and 210 mortality. ${ }^{78}$ Air pollution shows a dose-response association with ill-health, but beyond that, 211 those already affected by NCDs are also more susceptible to the harmful effects of air 212 pollution. ${ }^{90}$ Clearly, exposure to air pollution lies largely outside individual control and 213 represents a generic toxic environment (Box 2). 


\section{Urbanisation}

215 Urbanisation is one of the most important demographic shifts worldwide during the past 216 century. Today, more than half of the world's population resides in urban areas, representing 217 more than the world's total population in 1960. ${ }^{91}$ Between 2015 and 2030 the world will add 2181.1 billion new city dwellers, growing the global urban population by 28 per cent, from 4.0 219 billion to 5.1 billion. ${ }^{92,93}$ Furthermore, the majority of projected urban population growth will 220 be in Africa and Asia, followed by the Latin America and the Caribbean region. ${ }^{92,93}$

221 Within cities in LMICs, the majority of individuals simultaneously experience political, 222 economic, housing, and ecological vulnerability. ${ }^{94}$ Given the large number of individuals 223 residing in urban areas, these vulnerabilities translate into the majority of the population 224 being exposed to an environment that directly impacts their risk of cardiometabolic disease 225 and furthermore, within this environment there is inequitable access to opportunities for 226 healthy eating, active living and unpolluted environments; an inequity that exists both within 227 countries and compared to the same context within HICs.

228 The historical contexts around which cities in LMICs have developed have influenced the 229 vulnerabilities that persist, and continue to influence the nature of urbanisation in LMICs and 230 hence the risk of cardiometabolic disease development (Box 3). First, the urban centres of 231 many cities in Africa, Asia and Latin America are rooted in colonial legacies of sociopolitical 232 exclusion that manifest today as spatial inequalities that become evident in terms of 233 proximity to aspects of the city that are meant to confer an urban advantage, e.g. 234 infrastructure and amenities, and are consequently closely linked to health inequities. ${ }^{95}$ 235 Second, unplanned and unmanaged growth in rapidly growing LMIC cities creates 236 opportunities to live exceeding the opportunities for employment, along with high rates of 237 poverty, resulting in an urban form overwhelmingly characterised by conditions of informality, 238 for example, $62 \%$ of urban dwellers live in slum conditions in Africa. ${ }^{96}$ Last, the population 239 pyramids of LMICs highlight a distortion in urban versus rural populations with an increasing 240 proportion of adolescents and young people residing in cities, exposed to environments that 241 are not conducive to health-promoting behaviour. ${ }^{97}$

242 Despite being largely unplanned and illegal, informal settlements are persistent features of 243 the urban landscape of LMIC cities, with a growing proportion of the population living in such 244 settlements. ${ }^{98}$ In response, the New Urban Agenda ${ }^{99}$ adopted by the United Nations 245 Conference on Housing and Sustainable Urban Development and endorsed by the UN 246 General Assembly and the SDGs ${ }^{100}$ (Box 1) advocate for a shift away from eradication to 247 upgrading of informal settlements for inclusive human settlements (SDG 11), and health and 
248 wellbeing (SDG 3). Such healthy city interventions have primarily focused on improving 249 access to water and sanitation, ${ }^{101}$ with little or no focus on primary NCD prevention through

250 improving active living and healthy eating environments or reducing air pollution. One 251 example of a city in Africa taking the initiative to address unhealthy environments associated 252 with NCD risk is the collaboration between the city government of Accra, Ghana and the 253 World Health Organization (WHO) on an air pollution campaign. ${ }^{102}$ The poor urban 254 environment affects particularly the urban poor.

255 The WHO's Health-in-All-Policies approach ${ }^{103}$ aims to increase access to healthy, affordable 256 foods, opportunities for human interaction, and opportunities for physical activity; ${ }^{104}$ all of 257 which are driven by sectors outside of health or healthcare. These obesogenic elements of 258 the urban built environment that influence obesity and NCDs - high prevalence of energy 259 dense foods, marketing of unhealthy foods, lack of or limited footpaths/cycle infrastructure 260 and safe places to play, exposure to air pollution - are multiple, entangled, and 261 interconnected, and those living in informality are particularly vulnerable as they are least 262 equipped to compensate for the inextricable obesogenic conditions that epidemiological, 263 nutritional, and urban transitions generate. Informal built environments add complexity to 264 addressing the causes and complications of cardiometabolic disease as, for example, 265 interventions to address obesity may not be implemented through formal regulated 266 structures. $^{97}$

267 Nonetheless, cities can play a vital role in addressing health and social inequity; ${ }^{97,101,105}$ and 268 greater coordination across sectors could contribute to improving health outcomes. This 269 would require connection between relevant health indicators and urban infrastructure 270 initiatives, such as monitoring changes in the urban food environment and the impact of 271 these changes on healthy eating behaviour and cardiometabolic disease outcomes in the 272 long-term. For example, case studies have demonstrated how integrated urban planning can 273 support the development of equitable access to healthy food systems, and prevent food 274 deserts, where fresh food is unavailable, and only unhealthy, heavily processed foods high 275 in sugar, fat and carbohydrates are readily available and affordable. ${ }^{106}$

\section{Commercial determinants of health}

277 The etiology of cardiometabolic diseases is complex and influenced by different individual, 278 social, environmental and private sector determinants. ${ }^{107}$ The recent increased risks of 279 developing many of the major cardiometabolic diseases are associated with the production, 280 marketing, and consumption of commercially produced products, food and drinks - such as 281 those containing sugar, salt and trans-fats-, alcohol and tobacco. ${ }^{108}$ For example, the 
282 global adult per-capita consumption of alcohol per year increased from 5.9L to 6.5L between $2831990-2017$ and is projected to reach $7.6 \mathrm{~L}$ by $2030 ;{ }^{109}$ this includes a $104 \%$ increase in the 284 South-East Asian and a 54\% increase in the Western Pacific, regions as defined by the $285 \mathrm{WHO}$. This increase in alcohol use is especially high in upper middle-income countries such 286 as China, India and Vietnam where levels of alcohol consumption are higher than in some 287 European countries (Box 4). The growth of snacks, soft drinks and processed foods is also 288 fastest in LMICs compared to HICs and is projected to grow by $20 \%$ in the next 5 years; on 289 the other hand, little or no growth is expected in HICs. ${ }^{110}$

290 Commercial determinants of health are "strategies and approaches used by the private 291 sector to promote products and choices that are detrimental to health". ${ }^{111}$ This single 292 concept includes consumer and health behavior, individual choice at the micro level, global 293 risks to society, the global consumer society and the global economy at the macro level. In 294 fact, reaching any set target to reduce cardiometabolic disease will be challenging as long as 295 strategies and policies are not designed to govern the commercial drivers contributing to the 296 rising burden of cardiometabolic disease worldwide. As internationalization of trade, capital 297 and information in the food, beverage, and tobacco industries have substantially increased, 298 progress on preventing and controlling cardiometabolic diseases will require the public 299 health community to address industry responsibility in relation to the burden of 300 cardiometabolic diseases. ${ }^{110,112-114}$

301 The rise in consumption of unhealthy commodities reflects the fact that multinational 302 companies are increasingly targeting LMICs not only for their huge collective population size, 303 but also because governmental legislation protecting LMIC populations from unhealthy 304 commodities remains much weaker than in HICs, where the impacts on health are already 305 well recognised and supported by a strong scientific evidence base. ${ }^{26}$ The role of 306 commercial interests in negative health effects is highlighted by the promotion of private 307 vehicle ownership, which simultaneously increases air pollution whilst also undermining 308 physical activity patterns. ${ }^{115,116}$

309 Commercial influences may have both direct and indirect influences on cardiometabolic 310 diseases and contributory factors such as smoking, inactivity, and obesity; and these 311 influences often operate through long and complex causal pathways. The commercial 312 influences can also interact with one another, their contexts and society which has 313 implications for interventions at different levels. ${ }^{107}$ For example, researchers have identified 314 practices from industry-funded charities, such as the International Life Science Institute 315 (ILSI), an institute with the purported mission "to provide science that improves human 316 health and well being"117 that was founded and funded by Coca-cola and supported by 
317 McDonalds, Nestle and other corporate entities, against their purported objectives. Studies

318 found instances of ILSI seeking to influence research, conferences, public messages and

319 policy, including instances of punishments for related-bodies failing to promote industry-

320 favorable messaging. ${ }^{118}$

321 Similarly, children are important to industry marketers for many reasons: they often have

322 access to their own money to spend, they influence parental selection of products, and they

323 will grow up to be life-long consumers. ${ }^{119}$ Most families have televisions at home and

324 simultaneously, exposure to food advertisements has increased across all socioeconomic

325 groups. ${ }^{120-123}$ With the higher penetration of the Internet, new forms of food promotion are

326 being developed, particularly for children and adolescents. ${ }^{124,125}$ There is robust evidence

327 showing that unhealthy food products are more heavily advertised than healthier food

328 options; therefore, higher exposure to food marketing is likely promoting or sustaining

329 unhealthy dietary behaviors in LMICs, especially among children. ${ }^{126}$ Moreover, increasing

330 evidence indicates that food marketing has been changing its potential audience, now

331 targeting socio-economic and ethnic minorities and hence increasing the risk of widening

332 existing health and nutrition disparities. ${ }^{127}$

333 This generation of social collective harm is only one strategy being used to open new 334 markets in LMICs and promote the consumption of products linked to increased risk of 335 cardiometabolic disease. Industry also engages with and markets to stakeholders - people 336 with influence in the health policy and health investment world; as well as donors, policy 337 influencers, staffers, legislative aides, etc. - and politicians to influence the policy agenda 338 and undermine public health legislation. ${ }^{119}$ This has been quite effective for their work to 339 prevent industry regulation at national level (Box 4).

\section{Countering cardiometabolic diseases in LMICs}

\section{Population-based efforts}

342 Strategies to address cardiometabolic diseases in the majority of LMICs to date have 343 predominantly focused on the identification of risk factors as well as screening to detect and 344 treat diseases. ${ }^{128}$ Whilst these are important, there is a need for a greater focus on 345 prevention strategies that act on the upstream determinants. As NCDs have risen up the 346 global agenda, population-wide interventions merit attention. ${ }^{129}$ Population-wide preventive 347 strategies focus on intervening upon the determinants of health in large groups, with the aim 348 of shifting the whole population's distribution of a given risk factor. ${ }^{130-132}$ For example, 349 reducing sodium intake and eliminating the intake of artificial trans fatty acids has been 
350 proposed to delay 94 million deaths worldwide within 25 years. ${ }^{133}$ This has been recently 351 applied in Peru, where a pragmatic population-based approach using a salt substitution 352 strategy has shown community-wide reductions in levels of blood pressure as well as 353 reductions in the incidence of hypertension. ${ }^{134,135}$

354 Until recently, few examples of population-level interventions targeting cardiometabolic risk 355 factors in LMICs were available. As an example, the Framework Convention for Tobacco 356 Control (FCTC) provided a clear and systematic effort to include population-wide 357 interventions as a critical step to change the tide of tobacco consumption. The FCTC 358 proposed structural interventions, such as banning indoor smoking, increasing tobacco 359 prices, and restricting marketing channels to promote smoking, along with individual-level 360 interventions such as the provision of smoking cessation programs, to reduce tobacco361 related health problems. ${ }^{136}$ Its is now recognized that these strategies have been key to 362 stabilizing and reducing tobacco consumption globally, ${ }^{137}$ and in particular in LMICs such as 363 Mexico, ${ }^{138}$ Brazil, $^{136}$ or Thailand. ${ }^{139}$

364 Similar strategies to that of the FCTC are being implemented to reduce obesity and 365 metabolic diseases. Latin America has been at the forefront of the implementation of 366 interventions aimed at reducing the consumption of sugar sweetened beverages (SSBs) and 367 low-nutritional high-energy foods (junk food). The SSBs tax in Mexico was one of the first 368 nationwide taxes aimed at reducing the consumption of sugary drinks in the country; two 369 years after implementation, consumption decreased on average $8.2 \%$, while untaxed 370 beverages, such as water, increased $2.1 \%{ }^{140}$ These changes, along with the projections of 371 the potential impact of the tax in deaths, health care costs, and obesity and diabetes cases, 372 created momentum for the implementation of similar taxes in other countries, and to 373 consider doubling the current 1-peso-per-liter-tax in Mexico. ${ }^{141}$

374 More recently, Chile has set a global example in the implementation of a complete package 375 of structural interventions to curb obesity. ${ }^{142,143}$ In 2014 , Chile modified its previous sugar376 sweetened beverage tax, increasing the rate from $13 \%$ to $18 \%$ tax on industrialized 377 beverages with high levels of sugar (>6.25 g sugar/100 ml) and decreasing the rate from $37813 \%$ to $10 \%$ tax on industrialized beverages with low or no sugar. By 2016 , the country 379 implemented food labels to clearly identify foods and beverages high in sugars, calories, 380 sodium or saturated fats (now called "high-in" products). Simultaneously, the food 381 environment was regulated, banning the sales of these foods in schools and the marketing 382 of products in the media for children under 14 years of age. ${ }^{142-144}$ While the overarching 383 impact of these changes is still under analysis, recent studies have shown that people 384 understand well the labeling and that after implementation they improve food healthiness 
classification and decrease the purchases of "high-in" products of some food categories such as sweet-sugared beverages and breakfast cereals. Similarly, food-ad exposure on television decreased among preschoolers and adolescents and the exposure to unhealthy food products at the school also decreased substantially. Interestingly, it also seems that the food industry is responding to the onset of regulation by decreasing the amount of sugar and sodium in some food categories. Other countries in the Latin American and Caribbean region have approved similar policies, such as Uruguay and Peru. ${ }^{145,146}$

Efforts to regulate the obesogenic environment are closely linked with the urban health agenda in Latin America, ${ }^{147,148}$ and also to include the redesign of urban space and to provide better infrastructure to increase active transportation, reduce car use, provide green areas and increase public safety to incentivize utilitarian and leisure-time physical activity. ${ }^{149}$ Combating obesity requires integrated governmental and societal action to protect population health. ${ }^{150,151}$

\section{Improving healthcare}

LMICs have been facing major challenges regarding treating cardiometabolic diseases. Usually, health systems, especially the primary healthcare care level, are better prepared to respond to acute conditions, to provide maternal and child care, or to target prevention and control efforts oriented to infectious diseases. However, the response to chronic conditions is poorer mainly because, to combat these, people need frequent access to the health care system, have a good and long-term adherence to pharmacological and non-pharmacological treatment, and good coordination of care across levels of specialized treatment. In this context, different solutions have been proposed to strengthen the current health system, to implement different strategies to promote disease self-management or to identify stakeholders that can support the health system. ${ }^{152}$ Here we briefly mention the role of technologies and health (mHealth), integration of care, and task shifting, whose application has been highly innovative in LMIC settings.

mHealth has been applied in LMICs by different actors and with a diversity of purposes. For example, in terms of prevention of disease, particularly in weight reduction, patients and caregivers have been offered different types of technological support to promote behavioural change such as mobile phone apps, Web pages, and short messaging services (SMS) ${ }^{153-156}$ as reminders to increase adherence to lifestyle changes through improving knowledge and enhance motivation to change behaviour. ${ }^{157}$ On the other hand, health workers have been receiving training in the diagnosis and management of cardiometabolic diseases through 
419 eHealth, whereas in other cases, both in HIC and LMICs, health professionals in remote

420 areas have received support through telemedicine. ${ }^{23,158-161}$

421 Given the limitations and shortcomings of existing healthcare systems and infrastructure in 422 LMICs, be it in terms of budget, services and human resources, compounded with the 423 challenges of chronic conditions and multimorbidity, ${ }^{162}$ moving away from addressing single 424 diseases towards the integration of care seems to be a suitable response in LMICs. ${ }^{163-169}$ 425 Different projects have been working towards improving the health system, at all levels 426 (primary care, hospitals or specialized institutes) and working with all stakeholders (health 427 workers, managers, regional health directors) to improve access to care, increase availability 428 and affordability of medicines, improve coordination of care or improve patient 429 satisfaction. ${ }^{170-173}$ Given the comorbidity between mental health and cardiometabolic 430 conditions, some projects have promoted the opportunistic screening of mental health 431 disorders in this group of patients and their referral using existing resources. ${ }^{174}$ Other 432 ongoing initiatives are using mHealth technologies to treat mild to moderate depressive 433 symptoms among patients with cardiometabolic conditions. ${ }^{175}$

434 It is well known and commonly reported that health workers are overwhelmed by their daily 435 activities, and this is also true in LMICs. To overcome this, some initiatives have targeted the 436 transfer of some of the work of health workers to other key actors, i.e. community health 437 workers, caregivers, and others. ${ }^{176-180}$ Also, to address the shortage of physicians, task 438 shifting has been moved to other healthcare professionals, for example nurses to manage 439 hypertension. ${ }^{181}$ These strategies have usually been accompanied by training and 440 technological support, leveraging mobile technology, and have been used mostly to 441 diagnose or identify patients at risk. ${ }^{152,182,183}$

\section{Future directions}

\section{Intersectoral strategies}

444 Whilst both LMICs and HICs have rising trends of obesity and diabetes, cardiovascular 445 disease mortality is decreasing in HICs but not in LMICs. Strategies to reduce the increasing 446 burden of cardiometabolic diseases in LMICS are desperately needed. Recognizing the links 447 between NCDs and the wider development and economic agendas within LMICs policy 448 environments is crucial to counter NCDs. Among them, promoting leadership to champion 449 health issues in non-health sectors, such as agriculture, economics or trade is an urgent task 450 to ensure a health perspective in all policies. Long-term exposure to obesogenic and toxic 451 environments, including fundamental drivers such as the commercial determinants of health, 
452 will require comprehensive responses going well beyond the health sector. Industry is 453 wealthy, complex and heterogeneous, so public health organizations will need more than 454 simple facts to confront it. Addressing the role of industry in NCDs raises discomfort for 455 many institutions and policy makers, due to potential conflicts of interest and distrust towards 456 some companies. This does not mean that there is no potential to engage and partner with 457 industry, but such partnerships are complicated and raise potential ethical issues, especially 458 for those who generate evidence or policy around cardiometabolic diseases.

459 LMICs have historically suffered the double burden of malnutrition, leaving a long lasting 460 metabolic mark in their population. Understanding the role of the biological penalties 461 suffered by LMIC populations in early life may provide additional information to develop 462 population-wide prevention initiatives that complement existing individual high-risk 463 approaches. LMICs also host areas of conflict and are fragile states, introducing another 464 example of rapid changes that will affect the development and control of NCDs. ${ }^{184-186}$ LMIC 465 populations are also those most vulnerable to wider planetary injuries, including climate 466 change. . $^{2187,188}$ Efforts to prevent NCDs should not be considered as competing with other 467 health and development agendas, but can rather serve as a unifying force, ultimately driving 468 the common goal of improving peoples' wellbeing across the lifecourse.

469 We think that there is a need for multi-stakeholder -involving public, private, and civil 470 society sectors - dialogue platforms and mechanisms to support intersectoral policy action 471 plans that bring together sectors that influence NCDs and its risk factors, to ensure policies 472 are aligned to prevent cardiometabolic diseases. Such spaces are vital to bridge the gap 473 between those working to address the knowledge gaps such as researchers, actors 474 responsible for implementation at scale, such as policymakers and practitioners, and the 475 potential beneficiaries and advocates, which involves the wider society.

\section{Improved disease surveillance}

477 In addition to the intersectoral governance mechanism required, there is a need for 478 integrated surveillance of cardiometabolic disease risk that incorporates both individual-level 479 health outcomes and community-level health-determinant exposures. Whilst surveillance of 480 this nature using traditional survey methodologies is resource-intensive, ongoing advances 481 in technologies to capture area-level data on health determinants are noteworthy and should 482 be incorporated into NCD prevention efforts. For example, advances in earth observation 483 data derived from satellite imagery which are increasingly available at neighbourhood 484 scales ${ }^{189}$ could be harnessed to monitor relevant changes in the urban environment and the 485 health impact of built-environment interventions on healthy eating behaviour and NCD risk. 


\section{Prioritizing adolescents and youth}

487 There must also be a focus on reducing the exposure of adolescents and young people to 488 risk factors for cardiometabolic disease. Multi-faceted intersectoral efforts that seek to 489 intervene appropriately over a long-time period are crucial to reduce NCDs in children and 490 adolescents. This is particularly vital in considering strategies that target young people for 491 cardiometabolic disease prevention. Introducing healthier behaviours and protective factors 492 during childhood and adolescence can significantly change an individual's health trajectory 493 into adulthood. ${ }^{190,191}$ However, besides sexual and reproductive health, the majority of 494 adolescents do not perceive a need for NCD prevention, nor do they routinely access health 495 care. ${ }^{192-194}$ Therefore, there is a need for strategies that seek to identify ways to improve the 496 health of younger populations, which are not purely within the context of either the health 497 sector, or the household, or educational establishments. ${ }^{192,194}$ Such strategies would need to 498 be multisectoral, recognizing the interactions between environmental and economic factors, 499 social norms and personal choice. ${ }^{195}$

\section{Improving our understanding of complex systems}

501 Investing in the long-term understanding of NCD-related outcomes produced by LMIC 502 environments will be needed. Scientific research is a fundamental resource for informing 503 policy and decision making. The LMIC scientific community must seek to understand the rise 504 in cardiometabolic diseases in their regions to identify successful interventions to control 505 cardiometabolic diseases. This will require, at least, capacity in key and emergent disciplines 506 such as complex systems thinking, ${ }^{196}$ implementation science, ${ }^{197,198}$ and decision-based 507 models. $^{199,200}$

508 It is now clear that the key risk factors for cardiometabolic diseases arise in a heavily 509 interrelated physical, biological, social, and economic space. Given this complexity, we will 510 need to find creative solutions that generate the benefits we expect, without producing 511 negative reverberations in the rest of the system. Complex systems thinking provides an 512 appropriate conceptual and methodological framework to pose and solve some of these 513 issues; however, its use remains limited, even in HICs. ${ }^{201}$ Similarly, research in LMICs 514 remains mainly directed to simple etiological studies that try to uncover the causes of 515 diseases or their complications. For cardiometabolic diseases, a lot is already known about 516 prevention and treatment, but the implementation of these solutions is painfully slow. 517 Implementation science tries to close the gap between knowledge and practice, by 518 proposing specific frameworks and methods to translate, adapt, and facilitate the 519 implementation of proven interventions. ${ }^{202}$ As yet, few examples of implementation science 
520 departments in LMICs are available. ${ }^{203}$ Finally, mathematical models are increasingly being

521 used in the public health arena to help overcome data limitations, understand the dynamics

522 of complex problems, simulate different intervention scenarios, and provide long term

523 estimates of potential interventions. While some examples of these efforts produced in

524 LMICs exist, their use is still rare and is not fully embraced by the academic community. ${ }^{204}$

525 While imperfect, mathematical models can be informative for policy decision making and

526 extremely cost-effective for understanding the potential impacts of decisions at the

527 population level. However, such modeling requires strong interdisciplinary teams, capable of

528 bridging across methodological and conceptual differences, that are sorely lacking in LMIC

529 settings.

$530 \quad$ Funding

531 LMICs need to drive their research agenda and thrive on it, in order to achieve and secure 532 population gains given the large burden imposed by cardiometabolic diseases. Yet, sufficient 533 funding remains a challenge. Health priorities in LMICs are often different from those in 534 HICs. Local funding for the development of structural interventions to solve population health 535 issues remains scarce and new models of funding will be necessary. ${ }^{205}$ Maternal and child 536 health agendas have achieved significant advances, that the NCD agenda has yet to 537 replicate, in terms of the alignment of political will and development agendas accompanied 538 by adequate funding. ${ }^{206}$ To harness large population gains given the widespread nature of 539 NCDs, funding will likely not need to target cellular or molecular biology, but rather the 540 complexity of the interrelationships between humans, private capital, public interest, the role 541 of governments, and the ability of the civil society to collectively work towards a more 542 humane, equitable and sustainable world. Increasing the funding for population health 543 interventions is also needed. This funding would be needed to study the development and 544 evaluation of interventions, acknowledging their complexity, and how best to implement 545 them. Funding for the actual implementation and scaling-up of proven interventions will also 546 be necessary to guarantee advancements in cardiometabolic diseases, and NCDs in 547 general, in LMICs. 


\section{$548 \quad$ Figures}

\section{Figure 1. The capacity-load model}

550 The capacity-load model considers that NCDs arise through the inability to maintain

551 metabolic homeostasis (healthy blood pressure, glycemic control, arterial health), resulting in

552 the development of pathophysiological traits that eventually lead to overt disease. NCD risk

553 is directly shaped by many components of physiology and behaviour (shown in red). A wide

554 range of factors manifesting in the body, impose a 'metabolic load' that challenges

555 homeostasis, examples being obesity, sedentary behaviour, diets high in sugar or fat,

556 psychosocial stress, smoking and the response to infection. High load elevates NCD risk,

557 whereas low load reduces it. However, the 'metabolic capacity' for homeostasis is also

558 strongly shaped by patterns of growth and development during 'critical windows' in early life,

559 when many physiological traits relevant to homeostasis are determined. High capacity

560 protects against NCDs, whereas insults to metabolic capacity elevate risk. The primary

561 environmental influence during early critical windows is maternal phenotype. NCD risk thus

562 emerges through the interaction of metabolic capacity and load (red arrow). Beyond the

563 body, numerous components of the environment also shape NCD risk. Harsh environmental

564 factors (shown in orange) drive elevations in metabolic load, and deplete metabolic capacity.

565 Public health efforts (shown in green) aim to counter these effects, by promoting metabolic

566 capacity in early life (promoting maternal and infant health) and reducing metabolic load in

567 children, adolescents and adults (promoting healthy lifestyles). This integrative model serves

568 to understand how NCD risk is shaped both by developmental experience and by exposure

569 to many aspects of today's unhealthy environments. Simply put, 'the higher the load, and the

570 lower the capacity, the greater the NCD risk. ${ }^{207}$ 


\section{Boxes}

572

573

574

575

576

577

578

579

580

581

582

583

584

585

586

587

588

589

590

591

592

593

594

595

596

597

598

599

600

601

\section{Box 1. Sustainable Development Goals}

The Sustainable Development Goals (SDGs) were proposed by the United Nations as the blueprint to achieve a better and more sustainable future for all by $2030 .^{100}$ There are 17 SGDs and 169 SDG targets. Whilst all SDGs are interconnected, SDG 3 is specifically devoted ensure healthy lives and promote well-being for all at all ages, and its target 3.4 commits countries to reducing by one third premature mortality from NCDs. ${ }^{208}$

Because health is an integral part of human capital and a precondition, driver and outcome of sustainable development, SDG 3 is linked to around 50 health-related targets across the SDGs and the pledge to leave no one behind. ${ }^{209}$

South Asia has the worst air pollution worldwide, being home to 17 of the top 30 cities with the highest levels. ${ }^{210}$ Although a global problem, the manifestation of air pollution in countries such as India has some unique features that exacerbate cardiometabolic disorders. These include the large numbers of two-stroke vehicles, the combustion of lowerquality fuels, the open burning of solid fuel in residential cooking stoves, and poorly regulated industrial processes. ${ }^{211}$ One of the most widely investigated markers of air pollution is particulate matter of size $\leq 2.5$ micrometers (PM2.5). Over the last three decades, PM2.5 concentrations are estimated to have increased by $\sim 25 \%$ in the South Asian region, exacerbated by rapid rates of unregulated urbanisation and industrialisation, ${ }^{210,211}$ while the high density of urban settlements results in substantial population exposure to this stress. Even in rural areas, indoor air pollution remains substantial. Over $80 \%$ of the rural Indian population continues to burn biomass for home cooking and heating, ${ }^{212}$ though efforts are underway to reduce this practice. Poorer households are least likely to have access to cleaner fuels, and typically lack a separate kitchen area, resulting in high levels of household air pollution to which women and children are especially exposed. ${ }^{212}$ The consequence is that average daily exposure to concentrations of PM 2.5 in India consistently and substantially exceeds the World Health Organization (WHO) recommendations, primarily through household exposure in rural populations, and through outdoor exposure in urban areas. $^{210}$ 

for ill health in India, ${ }^{213}$ with higher levels of particulate matter associated in cross-sectional studies with the risk of hypertension, diabetes and cardiovascular disease, and with biomarkers of inflammation. ${ }^{214}$ In the city of Chennai, for example, the prevalence of diabetes was $77.5 \%$ higher (34.8\% vs $19.6 \%$ ) in areas of high versus low levels of PM2.5 exposure ${ }^{215}$ while in Delhi, higher daily levels of air pollution were associated with a $24 \%$ increase in emergency room visits for acute coronary events. ${ }^{216}$ Using long-term data from satellite records, premature deaths in India attributable to PM2.5 exposure increased by $\sim 40 \%$ between 1999 and 2014. These trends were driven primarily by increases in ischaemic heart disease and stroke, which increased by $40 \%$ and $48 \%$ respectively. ${ }^{217}$

At a mechanistic level, there is increasing evidence that air pollution impacts directly on cardio-metabolic risk markers, such as blood pressure and insulin resistance. In the Andhra Pradesh Children and Parents Study, exposure to PM2.5 was positively correlated with blood pressure and hypertension in women, though the associations were weaker in men. ${ }^{218}$ Another study in rural West Bengal found that cooking with biomass exacerbated systemic inflammation, oxidative stress, hypertension and tachycardia. ${ }^{219}$

In those who already have cardio-metabolic conditions, representing a large proportion of the Indian population, air pollution may worsen the progression of disease. For example, among diabetic patients studied in the city of Pune, exposure to air pollution was associated with poorer glycemic control and systemic inflammation, indicating the exacerbation of diabetes complications. ${ }^{20,221}$

Beyond its adverse metabolic impacts in adulthood, air pollution also generates detrimental effects on early growth and development, thus undermining the long-term metabolic capacity for homeostasis. For example, household air pollution has been associated with an increased risk of low birth weight and intrauterine growth delay in India, ${ }^{222,223}$ which propagates to shorter child height. ${ }^{224}$

Trends in air pollution in India are complex, and driven by many different factors associated with economic development. However, the resulting health problems clearly have commercial determinants. The decentralization that is characteristic of Indian cities has increased travel distances and encouraged a shift to motorized transportation, largely through private transport. Between 1981 and 2002 the number of motorized two-wheelers increased 14-fold, and the country currently has the largest sales of such vehicles worldwide. ${ }^{225}$ These sales overwhelm urban infrastructure, and persistent traffic congestion substantially elevates emissions. 
Khayelitsha is the largest informal township in Cape Town, South Africa. Home to almost half a million, predominantly black residents, the history of the establishment of Khayelitsha, which means "our new home" in isiXhosa language, dates back to the apartheid policies of racial segregation in South Africa.

Following the first racially segregated settlements established in the early 1900s, Khayelitsha was established in the mid-1980s as the legal residence for black Africans in Cape Town. ${ }^{95}$ Located on low-lying sand dunes beyond the urban boundaries of Cape Town, the settlement was planned to be isolated from the rest of the city. Whilst these segregation laws have since been abolished, with transition to democracy in the 1990s, the spatial marginalisation of Khayelitsha means that whilst there has been a growth of commercial formal and informal activity, the settlement remains characterised by high levels of unemployment, poverty and health outcomes significantly poorer than the national and city average. Of note, mortality from stroke, hypertensive disease and diabetes is higher than the average for Cape Town. ${ }^{226}$

These diseases are influenced by dietary and physical activity habits which are in turn enabled or impeded by the respective food and activity environments. In Khayelitsha, the food environment is characterised by food insecurity and poor dietary diversity with insufficient access to healthy food. ${ }^{227}$ The geographical inaccessibility, with many households having to travel long distances for food shopping, ${ }^{228}$ is exacerbated by inadequate access to electricity and inability to store perishable fresh foods like fruits and vegetables, even where market or non-market sources of these foods exist, and an environment unconducive for urban agriculture. These challenges mean that even when residents are aware of the health impact of high salt, high fat, processed foods, the agency to make health food choices is significantly diminished. A study exploring food insecurity in patients with hypertension or diabetes residing in Masiphumelele, another low-income informal township in Cape Town demonstrated that patients with cardiometabolic disease had a good understanding of the importance of a healthy diet in particular fruit and vegetables. ${ }^{229}$ In this study, patients describe receiving nutritional advice from clinic as part of their diabetes or hypertension clinical management which implied a level of choice that did not exist in reality, and a lack of acknowledgement on the part of clinicians of the lack of food choices in patients' contexts. Barriers to accessing these foods expressed included the cost, 669 short shelf-life, and poor quality of available fresh foods in their neighbourhoods. 
670

671

672

673

674

675

676

677

678

679

680

681

682

683

684

685

686

687

688

689

690

691

692

693

694

695

696

697

698

699

700

701
Similar barriers to physical activity are experienced in these informal settlements. In other words, whilst residents recognise the value of taking walks and exercise, the perceived and experienced threat of violence, lack of access to well-maintained open public spaces and playgrounds, and the lack of opportunity for active travel due to the remoteness of the location $^{228}$ conspire to result in insufficient levels of physical activity to reduce the risk of cardiometabolic disease.

These examples highlight the influence of the built environment, particularly in the context of informal settlements, on cardiometabolic risk. As the proportion of urban residents residing in conditions of informality continues to increase in Africa's rapidly growing cities, a recognition by clinicians of the importance of this urban exposure and a willingness to engage with urban design and planning sectors, which play a critical role, is vital to reduce these population health inequities.
One of the leading risk factors of deaths worldwide is the harmful use of alcohol, which is linked to over 200 diseases and injuries and can have social and economic implications for a country. ${ }^{230,231}$ In 2016, almost 5.3\% (3 million deaths) of all deaths worldwide were caused by harmful use of alcohol. ${ }^{232}$ According to recent statistics, alcohol is consumed by some 2.3 billion people worldwide, and the total per capita consumption has risen from 5.5 liters in 2005 to almost 6.4 liters in 2016. ${ }^{232}$ In 2016, an estimated 1.7 million NCD deaths and 65.5 million NCD DALYs were caused by alcohol consumption. ${ }^{232}$ Additionally, an estimated 0.9 million injury deaths and 52.4 million injury DALYs are attributed to alcohol. ${ }^{232}$

The risk from alcohol is associated with the production, marketing, and consumption of such products by commercial entities. ${ }^{108}$ Alcohol industry, similar to tobacco, exerts influence through four main channels: marketing, lobbying, corporate social responsibility strategies and extensive supply chains worldwide. ${ }^{111}$ One of the most impactful factors associated with alcohol consumption is alcohol marketing and its regulation has been identified by WHO as a "Best Buy" policy for reduction of harmful use of alcohol. ${ }^{233}$ While limited in number, existing studies show that the alcohol industry uses policy-influencing direct and indirect strategies; these include extensive lobbying, and attempts to shape public perceptions of alcohol and the scientific content of regulatory debates. ${ }^{234}$ For example, 23 grants were given to researchers by the industry in 13 countries over 6 years $^{235}$ that is why calls for researchers 
702 to sever financial ties with the alcohol industry and warnings about engaging with the alcohol 703 industry altogether have been issued. ${ }^{236,237}$

704

705

706

707

708

709

710

711

712

713

714

715

716

717

718

719

720

721

722

723

724

725

726

727

728

729

730

731

732

733

The alcohol industry also uses corporate social responsibility activities to define themselves as corporate citizens who are part of the policy solution; and organizations such as the International Alliance for Responsible Drinking, previously International Center for Alcohol Policies, are one of the main components of this strategy. ${ }^{234,238}$ For example, the alcohol industry has been promoting weak interventions to control drunk driving; a 2016 study showed that less than $1 \%$ of the industry's actions to reduce drunk driving aligned with evidence-based recommendations, ${ }^{239}$ and at the same time the industry increased its involvement in policymaking and scientific research. ${ }^{240}$

India in recent years, has seen a staggering increase in alcohol consumption, where the average adult per capita alcohol consumption increased by $19 \%$ between 2005 and $2010 .^{239}$ Diageo, a London based multinational alcohol corporation, is one of the largest sellers of alcohol spirits in India and has over $\$ 1.1$ billion of investment in the country. ${ }^{240}$ Diageo has employed various tactics to speed its growth in emerging markets like India. However, some of this growth involved contentious activities; for example, in 2011 Diageo was charged with major violations of the Foreign Corrupt Practices Act by the U.S. Securities and Exchange Commission; Diageo had paid over $\$ 1.7$ million to hundreds of Indian government officials. Diageo also uses strategic marketing to attract new, young consumers; for example, sale of alcohol in small sachets ("tetrapacks") or mini-bottles. Diageo also recognized a trend of growing alcohol consumption by Indian women and launched "a community investment program that aims to empower women through learning". ${ }^{241}$ These programs promote individual level, voluntary, behavior change strategies diverting investment and attention from effective public health strategies that modify the alcohol environment to reduce the misuse of alcohol. ${ }^{239}$

\section{Acknowledgements}

JJM conceived the idea of linking child survival and adult population handicaps that will affect responses to NCDs and climate change whilst supported through an Erasmus Mundus Scholar at KIT Royal Tropical Institute, Amsterdam, in 2013. This idea was further elaborated through interactions with William Pan, David Beran, and Fernando Maldonado, among others. 
734 JJM acknowledges having received support from the Alliance for Health Policy and Systems

735 Research (HQHSR1206660), the Bernard Lown Scholars in Cardiovascular Health Program

736 at Harvard T.H. Chan School of Public Health (BLSCHP-1902), Bloomberg Philanthropies,

737 FONDECYT via CIENCIACTIVA/CONCYTEC, British Council, British Embassy and the

738 Newton-Paulet Fund (223-2018, 224-2018), DFID/MRC/Wellcome Global Health Trials

739 (MR/M007405/1), Fogarty International Center (R21TW009982, D71TW010877), Grand

740 Challenges Canada (0335-04), International Development Research Center Canada (IDRC

741 106887, 108167), Inter-American Institute for Global Change Research (IAI CRN3036),

742 Medical Research Council (MR/P008984/1, MR/P024408/1, MR/P02386X/1), National

743 Cancer Institute (1P20CA217231), National Heart, Lung and Blood Institute

744 (HHSN268200900033C, 5U01HL114180, 1UM1HL134590), National Institute of Mental

745 Health (1U19MH098780), Swiss National Science Foundation (40P740-160366), Wellcome

$746 \quad(074833 / Z / 04 / Z, \quad 093541 / Z / 10 / Z, \quad 107435 / Z / 15 / Z, \quad 103994 / Z / 14 / Z, \quad 205177 / Z / 16 / Z$,

747 214185/Z/18/Z) and the World Diabetes Foundation (WDF15-1224).

748 TB-G was supported by Bloomberg Philanthropies, the Bernard Lown Scholars in

749 Cardiovascular Health Program at Harvard T.H. Chan School of Public Health, the "Fondo

750 Sectorial en Investigación en Salud y Seguridad Social" from the National Council for

751 Science and Technology of Mexico (CONACYT-FOSSIS-202671), and Wellcome

752 (205177/Z/16/Z).

753 CC receives a salary as Assistant Professor of INTA, University of Chile.

754 AAH did not receive external funding for this work but has internal support as Director, 755 Center on Commercial Determinants of Health, Milken Institute School of Public Health, 756 George Washington University. He has received support from numerous agencies including 757 current funding from the National Institutes of Health, Fogarty International Center, USA.

758 ML-P receives funding from the Swiss Excellence Government Scholarship (2018.0698).

759 TO is supported by the National Institute for Health Research (NIHR) Global Health 760 Research Group and Network on Diet and Activity. The views expressed in this publication 761 are those of the author and not necessarily those of the NHS, the National Institute for 762 Health Research or the Department of Health. Funding from NIHR (16/137/34) is gratefully 763 acknowledged. TO is also supported by the Stellenbosch Institute for Advanced Study Iso 764 Lomso Fellowship, and LIRA 2030 Africa Programme (LIRA2030-GR06/18), implemented by 765 the International Science Council (ISC) in partnership with the Network of African Science 766 Academies (NASAC) with support from the Swedish International Development Cooperation 767 Agency (Sida). 
768 JCKW receives a salary as Professor of University College London's Great Ormond Street 769 Institute of Child Health.

770 We acknowledge the support of Dr. Nino Paichadze and Dr. Imran Bari from the Milken

771 Institute School of Public Health, George Washington University, for their support with the 772 case study on alcohol.

773 


\section{References}

775 1. Horton, R. Offline: Time to radically rethink non-communicable diseases. Lancet 393,

$7761922(2019)$.

777 2. Nugent, R. \& Fottrell, E. Non-communicable diseases and climate change: linked global

778 emergencies. The Lancet (2019). doi:10.1016/s0140-6736(19)31762-3

779 3. Heller, O. et al. The process of prioritization of non-communicable diseases in the global 780 health policy arena. Health Policy Plan. 34, 370-383 (2019).

781 4. Bloom, D.E., Cafiero, E.T., Jané-Llopis, E., Abrahams-Gessel, S., Bloom, L.R., Fathima, 782 S., Feigl, A.B., Gaziano, T., Mowafi, M., Pandya, A., Prettner, K., Rosenberg, L., 783 Seligman, B., Stein, A.Z., \& Weinstein, C. The Global Economic Burden of $784 \quad$ Noncommunicable Diseases. (World Economic Forum, 2011).

785 5. Kelland, K. Chronic disease to cost $\$ 47$ trillion by 2030: WEF. Reuters (2011).

786 6. Nugent, R. et al. Investing in non-communicable disease prevention and management 787 to advance the Sustainable Development Goals. Lancet 391, 2029-2035 (2018).

788 7. Jaspers, L. et al. The global impact of non-communicable diseases on households and 789 impoverishment: a systematic review. Eur. J. Epidemiol. 30, 163-188 (2015).

790 8. Niessen, L. W. et al. Tackling socioeconomic inequalities and non-communicable 791 diseases in low-income and middle-income countries under the Sustainable 792 Development agenda. Lancet 391, 2036-2046 (2018).

793 9. Ghebreyesus, T. A. Acting on NCDs: counting the cost. The Lancet 391, 1973-1974 794 (2018).

795 10. Ezzati, M., Pearson-Stuttard, J., Bennett, J. E. \& Mathers, C. D. Acting on non796 communicable diseases in low- and middle-income tropical countries. Nature 559, 507$797 \quad 516(2018)$.

798 11. NCD Countdown 2030 collaborators. NCD Countdown 2030: worldwide trends in non799 communicable disease mortality and progress towards Sustainable Development Goal $800 \quad$ target 3.4. Lancet 392, 1072-1088 (2018). 
801

802

803

804

805

806

807

808

809

810

811

812

813

814

815

816

817

818

819

820

821

822

823

824

825

826

827

828

12. Ezzati, M. et al. Contributions of risk factors and medical care to cardiovascular mortality trends. Nat. Rev. Cardiol. 12, 508-530 (2015).

13. Roth, G. A. et al. Global, Regional, and National Burden of Cardiovascular Diseases for 10 Causes, 1990 to 2015. J. Am. Coll. Cardiol. 70, 1-25 (2017).

14. Mensah, G. A. et al. Decline in Cardiovascular Mortality: Possible Causes and Implications. Circ. Res. 120, 366-380 (2017).

15. Lackland, D. T. et al. Factors influencing the decline in stroke mortality: a statement from the American Heart Association/American Stroke Association. Stroke 45, 315-353 (2014).

16. Ford, E. S. \& Capewell, S. Proportion of the decline in cardiovascular mortality disease due to prevention versus treatment: public health versus clinical care. Annu. Rev. Public Health 32, 5-22 (2011).

17. NCD Risk Factor Collaboration (NCD-RisC). Worldwide trends in diabetes since 1980: a pooled analysis of 751 population-based studies with 4.4 million participants. Lancet 387, 1513-1530 (2016).

18. Gregg, E. W., Sattar, N. \& Ali, M. K. The changing face of diabetes complications. Lancet Diabetes Endocrinol 4, 537-547 (2016).

19. World Health Organization. Global Status Report on Noncommunicable Diseases 2014. (World Health Organization, 2015).

20. Benziger, C. P., Roth, G. A. \& Moran, A. E. The Global Burden of Disease Study and the Preventable Burden of NCD. Glob. Heart 11, 393-397 (2016).

21. Yusuf, S. et al. Modifiable risk factors, cardiovascular disease, and mortality in 155722 individuals from 21 high-income, middle-income, and low-income countries (PURE): a prospective cohort study. Lancet (2019). doi:10.1016/S0140-6736(19)32008-2

22. Yusuf, S. et al. Cardiovascular risk and events in 17 low-, middle-, and high-income countries. N. Engl. J. Med. 371, 818-827 (2014).

23. Bowry, A. D. K., Lewey, J., Dugani, S. B. \& Choudhry, N. K. The Burden of Cardiovascular Disease in Low- and Middle-Income Countries: Epidemiology and 
Management. Can. J. Cardiol. 31, 1151-1159 (2015).

24. World Heart Federation. Resources and tools to achieve 25 by 25 . WHF Global CVD Roadmaps Available at: http://www.cvdroadmaps.org/. (Accessed: 25th July 2019)

25. Wells, J. C. K. The thrifty phenotype: An adaptation in growth or metabolism? Am. J. Hum. Biol. 23, 65-75 (2011).

26. Wells, J. C. K. The Metabolic Ghetto: An Evolutionary Perspective on Nutrition, Power

30. Jaacks, L. M. et al. The obesity transition: stages of the global epidemic. Lancet Diabetes Endocrinol (2019). doi:10.1016/S2213-8587(19)30026-9

31. Brandkvist, M. et al. Quantifying the impact of genes on body mass index during the obesity epidemic: longitudinal findings from the HUNT Study. BMJ 366, 14067 (2019).

32. Omran, A. R. The epidemiologic transition. A theory of the epidemiology of population change. Milbank Mem. Fund Q. 49, 509-538 (1971).

33. Mendoza, W. \& Miranda, J. J. Global Shifts in Cardiovascular Disease, the Epidemiologic Transition, and Other Contributing Factors: Toward a New Practice of Global Health Cardiology. Cardiol. Clin. 35, 1-12 (2017).

34. Yusuf, S., Reddy, S., Ounpuu, S. \& Anand, S. Global burden of cardiovascular diseases: part I: general considerations, the epidemiologic transition, risk factors, and impact of urbanization. Circulation 104, 2746-2753 (2001). 
857

858

859

860

861

862

863

864

865

866

867

868

869

870

871

872

873

874

875

876

877

878

879

880

881

882

883

884

35. Wells, J. C. K. Maternal capital and the metabolic ghetto: An evolutionary perspective on the transgenerational basis of health inequalities. Am. J. Hum. Biol. 22, 1-17 (2010).

36. Unnikrishnan, R., Gupta, P. K. \& Mohan, V. Diabetes in South Asians: Phenotype, Clinical Presentation, and Natural History. Curr. Diab. Rep. 18, 30 (2018).

37. Pomeroy, E., Mushrif-Tripathy, V., Cole, T. J., Wells, J. C. K. \& Stock, J. T. Ancient origins of low lean mass among South Asians and implications for modern type 2 diabetes susceptibility. Sci. Rep. 9, 10515 (2019).

38. Black, R. E. et al. Maternal and child undernutrition: global and regional exposures and health consequences. Lancet 371, 243-260 (2008).

39. Martorell, R. Improved nutrition in the first 1000 days and adult human capital and health. Am. J. Hum. Biol. 29, (2017).

40. Victora, C. G. et al. Maternal and child undernutrition: consequences for adult health and human capital. Lancet 371, 340-357 (2008).

41. Hoddinott, J. et al. Adult consequences of growth failure in early childhood. Am. J. Clin. Nutr. 98, 1170-1178 (2013).

42. Smith, L. C. \& Haddad, L. Reducing Child Undernutrition: Past Drivers and Priorities for the Post-MDG Era. World Dev. 68, 180-204 (2015).

43. Cravioto, J., DeLicardie, E. R. \& Birch, H. G. Nutrition, Growth and Neurointegrative Development: An Experimental and Ecologic Study. Pediatrics 38, 319-320 (1966).

44. Crimmins, E. M. \& Finch, C. E. Infection, inflammation, height, and longevity. Proc. Natl. Acad. Sci. U. S. A. 103, 498-503 (2006).

45. Gluckman, P. D. \& Hanson, M. A. Living with the past: evolution, development, and patterns of disease. Science 305, 1733-1736 (2004).

46. Hernández-Cordero, S. et al. Overweight and obesity in Mexican children and adolescents during the last 25 years. Nutr. Diabetes 7, e280 (2017).

47. Kain, J., Uauy, R., Lera, L., Taibo, M. \& Albala, C. Trends in height and BMI of 6-yearold children during the nutrition transition in Chile. Obes. Res. 13, 2178-2186 (2005).

48. Perez-Escamilla, R. et al. Nutrition disparities and the global burden of malnutrition. 
BMJ 361, k2252 (2018).

49. Double burden of malnutrition. World Health Organization (2017). Available at: https://www.who.int/nutrition/double-burden-malnutrition/en/. (Accessed: 25th September 2019)

50. Webb, P. et al. Hunger and malnutrition in the 21st century. BMJ 361, k2238 (2018).

51. de Onis, M. \& Branca, F. Childhood stunting: a global perspective. Matern. Child Nutr. 12 Suppl 1, 12-26 (2016).

52. Department for International Development. Early childhood development and cognitive development in developing countries: A rigorous literature review. GOV.UK (2014). Available at: https://www.gov.uk/dfid-research-outputs/early-childhood-developmentand-cognitive-development-in-developing-countries-a-rigorous-literature-review. (Accessed: 22nd July 2019)

53. Miranda, J. J., Wells, J. C. K. \& Smeeth, L. [Transitions in context: findings related to rural-to-urban migration and chronic non-communicable diseases in Peru]. Rev. Peru. Med. Exp. Salud Publica 29, 366-372 (2012).

54. Miranda, J. J., Gilman, R. H. \& Smeeth, L. Differences in cardiovascular risk factors in rural, urban and rural-to-urban migrants in Peru. Heart 97, 787-796 (2011).

55. Hawkes, C. \& Popkin, B. M. Can the sustainable development goals reduce the burden of nutrition-related non-communicable diseases without truly addressing major food system reforms? BMC Med. 13, 143 (2015).

56. Swinburn, B. et al. INFORMAS (International Network for Food and Obesity/noncommunicable diseases Research, Monitoring and Action Support): overview and key principles. Obes. Rev. 14 Suppl 1, 1-12 (2013).

57. Popkin, B. M. \& Reardon, T. Obesity and the food system transformation in Latin America. Obes. Rev. 19, 1028-1064 (2018).

58. Baker, P. \& Friel, S. Food systems transformations, ultra-processed food markets and the nutrition transition in Asia. Global. Health 12, 80 (2016).

59. Vandevijvere, S. et al. Global trends in ultraprocessed food and drink product sales and 
913 their association with adult body mass index trajectories. Obes. Rev. (2019).

914 doi:10.1111/obr.12860

915 60. Monteiro, C. A. et al. Ultra-processed foods: what they are and how to identify them.

$916 \quad$ Public Health Nutr. 22, 936-941 (2019).

917 61. Carmo, A. S. do, Assis, M. M. de, Cunha, C. de F., Oliveira, T. R. P. R. de \& Mendes, L.

918 L. The food environment of Brazilian public and private schools. Cad. Saude Publica 34,

$919 \quad$ e00014918 (2018).

920 62. Pehlke, E. L., Letona, P., Hurley, K. \& Gittelsohn, J. Guatemalan school food

921 environment: impact on schoolchildren's risk of both undernutrition and

922 overweight/obesity. Health Promot. Int. 31, 542-550 (2016).

923 63. López-Barrón, R. G., Jiménez-Cruz, A. \& Bacardí-Gascón, M. Modifiable environmental 924 obesity risk factors among elementary school children in a Mexico-us border city. Nutr.

$925 \quad$ Hosp. 31, 2047-2053 (2015).

926 64. Corvalán, C. et al. Nutrition status of children in Latin America. Obes. Rev. 18 Suppl 2, $927 \quad 7-18(2017)$.

928 65. Parra, D. C. et al. Association between ultra-processed food consumption and the 929 nutrient profile of the Colombian diet in 2005. Salud Publica Mex. 61, 147-154 (2019).

930 66. Marrón-Ponce, J. A., Flores, M., Cediel, G., Monteiro, C. A. \& Batis, C. Associations 931 between Consumption of Ultra-Processed Foods and Intake of Nutrients Related to 932 Chronic Non-Communicable Diseases in Mexico. J. Acad. Nutr. Diet. (2019).

933 doi:10.1016/j.jand.2019.04.020

934 67. Louzada, M. L. da C. et al. The share of ultra-processed foods determines the overall 935 nutritional quality of diets in Brazil. Public Health Nutr. 21, 94-102 (2018).

936 68. Cediel, G. et al. Ultra-processed foods and added sugars in the Chilean diet (2010).

$937 \quad$ Public Health Nutr. 21, 125-133 (2018).

938 69. Dunford, E. K. et al. A comparison of the healthiness of packaged foods and beverages 939 from 12 countries using the Health Star Rating nutrient profiling system, 2013-2018.

940 Obes. Rev. (2019). doi:10.1111/obr.12879 
941 70. Pries, A. M. et al. Consumption of commercially produced snack foods and sugar-

942 sweetened beverages during the complementary feeding period in four African and

943 Asian urban contexts. Matern. Child Nutr. 13 Suppl 2, (2017).

944 71. Headey, D. D. \& Alderman, H. H. The Relative Caloric Prices of Healthy and Unhealthy

945 Foods Differ Systematically across Income Levels and Continents. J. Nutr. (2019).

946 doi:10.1093/jn/nxz158

947 72. Pan American Health Organization. Ultra-processed food and drink products in Latin

$948 \quad$ America: Trends, impact on obesity, policy implications. (PAHO, 2105).

949 73. Martínez Steele, E., Juul, F., Neri, D., Rauber, F. \& Monteiro, C. A. Dietary share of

950 ultra-processed foods and metabolic syndrome in the US adult population. Prev. Med.

$951 \quad 125,40-48(2019)$.

952 74. Srour, B. et al. Ultra-processed food intake and risk of cardiovascular disease:

953 prospective cohort study (NutriNet-Santé). BMJ 365, I1451 (2019).

954 75. Schnabel, L. et al. Association Between Ultraprocessed Food Consumption and Risk of

955 Mortality Among Middle-aged Adults in France. JAMA Intern. Med. (2019).

956 doi:10.1001/jamainternmed.2018.7289

957 76. Popkin, B. M. Rural areas drive increases in global obesity. Nature 569, 200-201

$958 \quad$ (2019).

959 77. Mannucci, P. M. \& Franchini, M. Health Effects of Ambient Air Pollution in Developing

960 Countries. Int. J. Environ. Res. Public Health 14, (2017).

961 78. Schraufnagel, D. E. et al. Air Pollution and Noncommunicable Diseases: A Review by

962 the Forum of International Respiratory Societies' Environmental Committee, Part 2: Air

$963 \quad$ Pollution and Organ Systems. Chest 155, 417-426 (2019).

964 79. World Health Organization. Ambient air pollution: A global assessment of exposure and 965 burden of disease. (World Health Organization, 2016).

966 80. Bonjour, S. et al. Solid fuel use for household cooking: country and regional estimates

967 for 1980-2010. Environ. Health Perspect. 121, 784-790 (2013).

968 81. GBD 2017 Risk Factor Collaborators. Global, regional, and national comparative risk 
assessment of 84 behavioural, environmental and occupational, and metabolic risks or clusters of risks for 195 countries and territories, 1990-2017: a systematic analysis for the Global Burden of Disease Study 2017. Lancet 392, 1923-1994 (2018).

82. Takeshita, T. Global scenarios of air pollutant emissions from road transport through to 2050. Int. J. Environ. Res. Public Health 8, 3032-3062 (2011).

83. Health effects of transport-related air pollution. (World Health Organization, Regional Office for Europe, 2005).

84. Grote, M., Williams, I., Preston, J. \& Kemp, S. Including congestion effects in urban road traffic $\mathrm{CO} 2$ emissions modelling: Do Local Government Authorities have the right options? Transp. Res. Part D: Trans. Environ. 43, 95-106 (2016).

85. Quadrelli, R. \& Peterson, S. The energy-climate challenge: Recent trends in CO2

87. Kinney, P. L. et al. Traffic Impacts on PM(2.5) Air Quality in Nairobi, Kenya. Environ. Sci. Policy 14, 369-378 (2011).

88. Wang, J. et al. Vehicle emission and atmospheric pollution in China: problems, progress, and prospects. PeerJ 7, e6932 (2019).

89. Ambient and Household Air Pollution and Health: Frequently Asked Questions. Pan American Health Organization / World Health Organization (2018). Available at: https://www.paho.org/hq/index.php?option=com_content\&view=article\&id=14454:ambie nt-and-household-air-pollution-and-health-frequently-askedquestions\&ltemid=72243\&lang=en. (Accessed: 2nd October 2019)

90. Schraufnagel, D. E. et al. Air Pollution and Noncommunicable Diseases: A Review by the Forum of International Respiratory Societies' Environmental Committee, Part 1: The Damaging Effects of Air Pollution. Chest 155, 409-416 (2019).

91. United Nations, Department of Economic and Social Affairs, Population Division. World Urbanization Prospects. The 2009 Revision. (United Nations, 2010). 
997 92. United Nations, Department of Economic and Social Affairs, Population Division.

998 Population 2030: Demographic challenges and opportunities for sustainable

999 development planning. (United Nations, 2015).

1000 93. United Nations, Department of Economic and Social Affairs, Population Division. World

$1001 \quad$ Urbanization Prospects: The 2014 Revision. (United Nations, 2014).

1002 94. Simone, A. \& Pieterse, E. New urban worlds: Inhabiting dissonant times. (John Wiley \& 1003 Sons, 2018).

1004 95. Cook, G. P. Khayelitsha: Policy Change or Crisis Response? Transactions of the 1005 Institute of British Geographers 11, 57-66 (1986).

1006 96. UN-Habitat. The State of African Cities 2014: Re-Imagining Sustainable Urban 1007 Transitions. (UN-Habitat, 2015).

1008 97. Vearey, J., Luginaah, I., Magitta, N. F., Shilla, D. J. \& Oni, T. Urban health in Africa: a 1009 critical global public health priority. BMC Public Health 19, 340 (2019).

1010 98. World Bank Open Data. World Bank Available at: https://data.worldbank.org/.

$1011 \quad$ (Accessed: 2nd October 2019)

1012 99. The New Urban Agenda. Habitat III Available at: http://habitat3.org/the-new-urban-

1013 agenda/. (Accessed: 2nd July 2019)

1014 100.United Nations. Sustainable Development Goals. United Nations Sustainable

1015 Development Goals Available at:

1016 https://www.un.org/sustainabledevelopment/sustainable-development-goals/.

1017 (Accessed: 2nd July 2019)

1018 101. Healthy Cities Initiative in the African Region: Evaluation Manual. (World Health

1019 Organization, Regional Office for Africa).

1020 102.Accra, Ghana is first African city to join the BreatheLife campaign. BreatheLife 2030

1021 Available at: https://breathelife2030.org/news/accra-ghana-first-african-city-join-

1022 breathelife-campaign/. (Accessed: 25th September 2019)

1023 103. Health in All Policies: Framework for Country Action. World Health Organization (2016).

1024 Available at: https://www.who.int/healthpromotion/frameworkforcountryaction/en/. 
(Accessed: 25th September 2019)

104.World Health Organization. Health as the pulse of the new urban agenda: United Nations conference on housing and sustainable urban development, Quito, October 2016. (2016). Available at: https://apps.who.int/iris/bitstream/handle/10665/250367/9789241511445-eng.pdf. (Accessed: 2nd July 2019)

105. Triana, C. A. et al. Active streets for children: The case of the Bogotá Ciclovía. PLoS

1032 One 14, e0207791 (2019).

106. World Health Organization \& UN-Habitat. Global report on urban health: equitable healthier cities for sustainable development. (World Health Organization, 2016).

107.Knai, C. et al. Systems Thinking as a Framework for Analyzing Commercial

1036 Determinants of Health. Milbank Q. 96, 472-498 (2018).

108.Buse, K., Tanaka, S. \& Hawkes, S. Healthy people and healthy profits? Elaborating a conceptual framework for governing the commercial determinants of non-communicable diseases and identifying options for reducing risk exposure. Global. Health 13, 34 (2017).

109. Manthey, J. et al. Global alcohol exposure between 1990 and 2017 and forecasts until 1042 2030: a modelling study. Lancet 393, 2493-2502 (2019).

110.Stuckler, D., McKee, M., Ebrahim, S. \& Basu, S. Manufacturing epidemics: the role of global producers in increased consumption of unhealthy commodities including processed foods, alcohol, and tobacco. PLoS Med. 9, e1001235 (2012).

111. Kickbusch, I., Allen, L. \& Franz, C. The commercial determinants of health. Lancet Glob Health 4, e895-e896 (2016).

112.Franz, C. \& Kickbusch, I. The Capital NCD-Nexus: The Commercial Determinants of Health and Global Capital Flows. Eurohealth 24, 21-25 (2018).

113. Moodie, R. et al. Profits and pandemics: prevention of harmful effects of tobacco, alcohol, and ultra-processed food and drink industries. Lancet 381, 670-679 (2013).

1052 114.Freudenberg, N. \& Galea, S. The impact of corporate practices on health: implications 
1053 for health policy. J. Public Health Policy 29, 86-104; discussion 105 (2008).

1054 115.Sá, T. H. de et al. Health impact modelling of different travel patterns on physical

1055 activity, air pollution and road injuries for São Paulo, Brazil. Environ. Int. 108, 22-31

$1056 \quad$ (2017).

1057 116.Zapata-Diomedi, B. et al. A shift from motorised travel to active transport: What are the 1058 potential health gains for an Australian city? PLoS One 12, e0184799 (2017).

1059 117. Mission \& Operating Principles. ILSI Available at: https://ilsi.org/about/mission/.

$1060 \quad$ (Accessed: 3rd October 2019)

1061 118.Steele, S., Ruskin, G., Sarcevic, L., McKee, M. \& Stuckler, D. Are industry-funded

1062 charities promoting 'advocacy-led studies' or 'evidence-based science'?: a case study of

1063 the International Life Sciences Institute. Global. Health 15, 36 (2019).

1064 119. Hastings, G. Why corporate power is a public health priority. BMJ 345, e5124 (2012).

1065 120.Allemandi, L., Castronuovo, L., Tiscornia, M. V., Ponce, M. \& Schoj, V. Food advertising

1066 on Argentinean television: are ultra-processed foods in the lead? Public Health Nutr. 21,

$1067 \quad 238-246(2018)$.

1068 121.Busse, P. \& Díaz, R. What are the television viewing and eating habits of children in

1069 Peru? Glob. Health Promot. 23, 50-60 (2016).

1070 122.Correa, T., Reyes, M., Smith Taillie, L. P. \& Dillman Carpentier, F. R. The prevalence

1071 and audience reach of food and beverage advertising on Chilean television according to

1072 marketing tactics and nutritional quality of products. Public Health Nutr. 22, 1113-1124

1073 (2019).

1074 123.Bacardí-Gascón, M. \& Jiménez-Cruz, A. Tv food advertising geared to children in Latin-

1075 American countries and Hispanics in the USA: a review. Nutr. Hosp. 31, 1928-1935

$1076 \quad$ (2015).

1077 124.Smith, R., Kelly, B., Yeatman, H. \& Boyland, E. Food Marketing Influences Children's

1078 Attitudes, Preferences and Consumption: A Systematic Critical Review. Nutrients 11,

1079 (2019).

1080 125. Mediano Stoltze, F. et al. Prevalence of child-directed and general audience marketing 
strategies on the front of beverage packaging: the case of Chile. Public Health Nutr. 21, 454-464 (2018).

126. Kelly, B. et al. Global benchmarking of children's exposure to television advertising of unhealthy foods and beverages across 22 countries. Obes. Rev. (2019). doi:10.1111/obr.12840

127. Harris, J. L., Frazier, W., III, Kumanyika, S. \& Ramirez, A. G. Increasing disparities in unhealthy food advertising targeted to Hispanic and Black youth. (Rudd Center for Food Policy \& Obesity, University of Connecticut; Drexel University; Salud America!, University of Texas Health Science Center at San Antonio, 2019).

128. Noncommunicable diseases. Key facts. World Health Organization Available at: https://www.who.int/news-room/fact-sheets/detail/noncommunicable-diseases. (Accessed: 26th September 2019)

129.Stuckler, D., Siegel, K., De Vogli, R. \& Basu, S. Chapter 2. Sick individuals, sick populations: The societal determinants of chronic diseases. in Sick Societies: Responding to the global challenge of chronic disease (eds. Stuckler, D. \& Siegel, K.) 26-62 (Oxford University Press, 2011).

130. Rose, G. Sick individuals and sick populations. Int. J. Epidemiol. 14, 32-38 (1985).

131. Frieden, T. R. A framework for public health action: the health impact pyramid. Am. J. Public Health 100, 590-595 (2010).

132. Stuckler, D. et al. Chapter 4. Comprehensive strategies to reduce the burden of chronic diseases. in Sick Societies: Responding to the global challenge of chronic disease (eds. Stuckler, D. \& Siegel, K.) 87-134 (Oxford University Press, 2011).

133. Kontis, V. et al. Three Public Health Interventions Could Save 94 Million Lives in 25 Years Global Impact Assessment Analysis. Circulation (2019). doi:10.1161/CIRCULATIONAHA.118.038160

134.A population-based salt-substitution strategy slashes hypertension risk. European Society of Cardiology (2019). Available at: https://www.escardio.org/Congresses-\&Events/ESC-Congress/Congress-resources/Congress-news/a-population-based-salt- 
substitution-strategy-slashes-hypertension-risk. (Accessed: 26th September 2019)

135. Community-based salt substitution programme lowers blood pressure. European

1111 Society of Cardiology Available at: https://www.escardio.org/The-ESC/Press-

1112 Office/Press-releases/community-based-salt-substitution-programme-lowers-blood-

1113 pressure. (Accessed: 26th September 2019)

1114 136. Levy, D., de Almeida, L. M. \& Szklo, A. The Brazil SimSmoke policy simulation model:

1115 the effect of strong tobacco control policies on smoking prevalence and smoking-

1116 attributable deaths in a middle income nation. PLoS Med. 9, e1001336 (2012).

1117 137.Warner, K. E. Tobacco control policies and their impacts. Past, present, and future. Ann.

$1118 \quad$ Am. Thorac. Soc. 11, 227-230 (2014).

1119 138. Reynales-Shigematsu, L. M. et al. Effects of tobacco control policies on smoking

1120 prevalence and tobacco-attributable deaths in Mexico: the SimSmoke model. Rev.

$1121 \quad$ Panam. Salud Publica 38, 316-325 (2015).

1122 139.Levy, D. T., Benjakul, S., Ross, H. \& Ritthiphakdee, B. The role of tobacco control

1123 policies in reducing smoking and deaths in a middle income nation: results from the

1124 Thailand SimSmoke simulation model. Tob. Control 17, 53-59 (2008).

1125 140.Colchero, M. A., Rivera-Dommarco, J., Popkin, B. M. \& Ng, S. W. In Mexico, Evidence

1126 Of Sustained Consumer Response Two Years After Implementing A Sugar-Sweetened

1127 Beverage Tax. Health Aff (Millwood) 36, 564-571 (2017).

1128 141.Barrientos-Gutiérrez, T., Colchero, M. A., Sánchez-Romero, L. M., Batis, C. \& Rivera-

1129 Dommarco, J. [Position paper on taxes to non-basic energy-dense foods and sugar-

1130 sweetened beverages]. Salud Publica Mex. 60, 586-591 (2018).

1131 142.Reyes, M. et al. Development of the Chilean front-of-package food warning label. BMC

$1132 \quad$ Public Health 19, 906 (2019).

1133 143.Corvalán, C., Reyes, M., Garmendia, M. L. \& Uauy, R. Structural responses to the 1134 obesity and non-communicable diseases epidemic: Update on the Chilean law of food 1135 labelling and advertising. Obes. Rev. 20, 367-374 (2019).

1136 144. Massri, C., Sutherland, S., Källestål, C. \& Peña, S. Impact of the Food-Labeling and 
Advertising Law Banning Competitive Food and Beverages in Chilean Public Schools, 2014-2016. Am. J. Public Health e1-e6 (2019).

145. Octógonos para etiquetado de alimentos. Ministerio de Salud Pública (2018). Available

1140 at: https://www.gub.uy/ministerio-salud-publica/comunicacion/noticias/octogonos-para-

1141 etiquetado-de-alimentos. (Accessed: 24th July 2019)

1142 146. Ministerio de Salud - Conoce las advertencias publicitarias (octógonos). (2019).

1143 Available at: https://www.gob.pe/1066-ministerio-de-salud-conoce-las-advertencias-

1144 publicitarias-octogonos. (Accessed: 24th July 2019)

1145 147.Quistberg, D. A. et al. Building a Data Platform for Cross-Country Urban Health Studies:

1146 the SALURBAL Study. J. Urban Health 96, 311-337 (2019).

1147 148.Diez Roux, A. V. et al. A Novel International Partnership for Actionable Evidence on

1148 Urban Health in Latin America: LAC Urban Health and SALURBAL. Global Challenges

$1149 \quad 3,1800013(2019)$.

1150

1151

1152

149. Towards more physical activity: Transforming public spaces to promote physical activity - a key contributor to achieving the Sustainable Development Goals in Europe. (World Health Organization Regional Office for Europe, European Commission, 2017).

150.Wells, J. C. K. Obesity as malnutrition: the dimensions beyond energy balance. Eur. J. Clin. Nutr. 67, 507-512 (2013).

151.Wallace, C. et al. Dimensions of national culture associated with different trajectories of male and female mean body mass index in countries over 25 years. Obes. Rev. (2019). doi:10.1111/obr.12884

152. Vedanthan, R. et al. Innovative Approaches to Hypertension Control in Low- and Middle-Income Countries. Cardiol. Clin. 35, 99-115 (2017).

153.Lombard, C. et al. Preventing Weight Gain in Women in Rural Communities: A Cluster Randomised Controlled Trial. PLoS Med. 13, e1001941 (2016).

154. Rubinstein, A. et al. Effectiveness of an mHealth intervention to improve the cardiometabolic profile of people with prehypertension in low-resource urban settings in Latin America: a randomised controlled trial. Lancet Diabetes Endocrinol 4, 52-63 
(2016).

155. Carrillo-Larco, R. M. et al. Implementation Tells Us More Beyond Pooled Estimates:

1167 Secondary Analysis of a Multicountry mHealth Trial to Reduce Blood Pressure. JMIR

$1168 \quad$ Mhealth Uhealth 6, e10226 (2018).

1169 156. Fottrell, E. et al. Community groups or mobile phone messaging to prevent and control

1170 type 2 diabetes and intermediate hyperglycaemia in Bangladesh (DMagic): a cluster-

1171 randomised controlled trial. Lancet Diabetes Endocrinol 7, 200-212 (2019).

1172 157.Beratarrechea, A. et al. Use of m-Health Technology for Preventive Interventions to

1173 Tackle Cardiometabolic Conditions and Other Non-Communicable Diseases in Latin

1174 America- Challenges and Opportunities. Prog. Cardiovasc. Dis. 58, 661-673 (2016).

1175 158.Mileski, M., Kruse, C. S., Catalani, J. \& Haderer, T. Adopting Telemedicine for the Self-

1176 Management of Hypertension: Systematic Review. JMIR Med Inform 5, e41 (2017).

1177 159.Zanaboni, P. \& Wootton, R. Adoption of telemedicine: from pilot stage to routine

1178 delivery. BMC Med. Inform. Decis. Mak. 12, 1 (2012).

1179 160.Inglis, S. C. et al. Structured telephone support or telemonitoring programmes for

1180 patients with chronic heart failure. Cochrane Database Syst. Rev. CD007228 (2010).

1181 161.Ekeland, A. G., Bowes, A. \& Flottorp, S. Effectiveness of telemedicine: a systematic

1182 review of reviews. Int. J. Med. Inform. 79, 736-771 (2010).

1183 162.Academy of Medical Sciences. Multiple morbidities as a global health challenge.

$1184 \quad$ (Academy of Medical Sciences, 2015).

1185 163.Navickas, R., Petric, V.-K., Feigl, A. B. \& Seychell, M. Multimorbidity: What do we

1186 know? What should we do? Journal of Comorbidity 6, 4-11 (2016).

1187 164. Hurst, J. R. et al. Global Alliance for Chronic Disease researchers' statement on

1188 multimorbidity. Lancet Glob Health 6, e1270-e1271 (2018).

1189 165.Woltmann, E. et al. Comparative effectiveness of collaborative chronic care models for

1190 mental health conditions across primary, specialty, and behavioral health care settings:

1191 systematic review and meta-analysis. Am. J. Psychiatry 169, 790-804 (2012).

1192 166.Diez-Canseco, F. et al. [Integration of mental health and chronic non-communicable 
diseases in Peru: challenges and opportunities for primary care settings]. Rev. Peru. Med. Exp. Salud Publica 31, 131-136 (2014).

167.Stein, D. J. et al. Integrating mental health with other non-communicable diseases. BMJ 364, 1295 (2019).

168. Mounier-Jack, S., Mayhew, S. H. \& Mays, N. Integrated care: learning between high1198 income, and low- and middle-income country health systems. Health Policy Plan. 32, $1199 \quad$ iv6-iv12 (2017).

169.Druetz, T. Integrated primary health care in low- and middle-income countries: a double 1201 challenge. BMC Med. Ethics 19, 48 (2018).

1202 170.Lee, E. S. et al. Quality Improvement for Cardiovascular Disease Care in Low- and 1203 Middle-Income Countries: A Systematic Review. PLoS One 11, e0157036 (2016). 1204 171. Ojo, T. et al. Feasibility of integrated, multilevel care for cardiovascular diseases (CVD) and HIV in low- and middle-income countries (LMICs): A scoping review. PLoS One 14, e0212296 (2019).

172. World Health Organization. Package of essential noncommunicable (PEN) disease interventions for primary health care in low-resource settings. (World Health Organization, 2010).

173. Hui, R. L. et al. Evaluation of a Pharmacist-Managed Antidiabetic Deprescribing Program in an Integrated Health Care System. J Manag Care Spec Pharm 25, 927-934 (2019).

174.Diez-Canseco, F. et al. Integration of a Technology-Based Mental Health Screening Program Into Routine Practices of Primary Health Care Services in Peru (The Allillanchu

1219 176.Peiris, D. et al. SMARThealth India: A stepped-wedge, cluster randomised controlled 1220 trial of a community health worker managed mobile health intervention for people 
assessed at high cardiovascular disease risk in rural India. PLoS One 14, e0213708 (2019).

177.Limbani, F., Thorogood, M., Gómez-Olivé, F. X., Kabudula, C. \& Goudge, J. Task shifting to improve the provision of integrated chronic care: realist evaluation of a lay health worker intervention in rural South Africa. BMJ Glob Health 4, e001084 (2019).

178. Tian, M. et al. A Cluster-Randomized, Controlled Trial of a Simplified Multifaceted Management Program for Individuals at High Cardiovascular Risk (SimCard Trial) in Rural Tibet, China, and Haryana, India. Circulation 132, 815-824 (2015).

179. He, J. et al. Effect of a Community Health Worker-Led Multicomponent Intervention on Blood Pressure Control in Low-Income Patients in Argentina: A Randomized Clinical Trial. JAMA 318, 1016-1025 (2017).

180. Egbujie, B. A. et al. Role of community health workers in type 2 diabetes mellitus selfmanagement: A scoping review. PLoS One 13, e0198424 (2018).

181. Ogedegbe, G. et al. Health insurance coverage with or without a nurse-led task shifting strategy for hypertension control: A pragmatic cluster randomized trial in Ghana. PLoS Med. 15, e1002561 (2018).

182.Joshi, R. et al. Task-shifting for cardiovascular risk factor management: lessons from the Global Alliance for Chronic Diseases. BMJ Glob Health 3, e001092 (2018).

183. Beratarrechea, A. et al. Using mHealth Tools to Improve Access and Coverage of People With Public Health Insurance and High Cardiovascular Disease Risk in Argentina: A Pragmatic Cluster Randomized Trial. J. Am. Heart Assoc. 8, e011799 (2019).

184.Ruby, A., Knight, A., Perel, P., Blanchet, K. \& Roberts, B. The Effectiveness of Interventions for Non-Communicable Diseases in Humanitarian Crises: A Systematic Review. PLoS One 10, e0138303 (2015).

185. Jobanputra, K., Boulle, P., Roberts, B. \& Perel, P. Three Steps to Improve Management of Noncommunicable Diseases in Humanitarian Crises. PLoS Med. 13, e1002180 (2016). 
186. Demaio, A., Jamieson, J., Horn, R., de Courten, M. \& Tellier, S. Non-communicable diseases in emergencies: a call to action. PLoS Curr. 5, (2013).

187. Swinburn, B. A. et al. The Global Syndemic of Obesity, Undernutrition, and Climate Change: The Lancet Commission report. Lancet 393, 791-846 (2019).

188. Friel, S. et al. Climate change, noncommunicable diseases, and development: the relationships and common policy opportunities. Annu. Rev. Public Health 32, 133-147 (2011).

189. Thomson, D. R. et al. Extending Data for Urban Health Decision-Making: a Menu of New and Potential Neighborhood-Level Health Determinants Datasets in LMICs. J. Urban Health (2019). doi:10.1007/s11524-019-00363-3

190. Johnson, R. C. \& Schoeni, R. F. Early-life origins of adult disease: national longitudinal population-based study of the United States. Am. J. Public Health 101, 2317-2324 (2011).

191.Wang, G., Walker, S. O., Hong, X., Bartell, T. R. \& Wang, X. Epigenetics and early life origins of chronic noncommunicable diseases. J. Adolesc. Health 52, S14-21 (2013).

192. Adolescent responsive health systems. World Health Organization (2015). Available at: https://www.who.int/maternal_child_adolescent/topics/adolescence/health_services/en/. (Accessed: 26th September 2019)

193. Mikkelsen, B. et al. Life course approach to prevention and control of noncommunicable diseases. BMJ 364, I257 (2019).

194.Laski, L. \& Expert Consultative Group for Every Woman Every Child on Adolescent Health. Realising the health and wellbeing of adolescents. BMJ 351, h4119 (2015).

195. World Health Organization. Global strategy on diet, physical activity and health. World Health Organization (2004). Available at: https://www.who.int/dietphysicalactivity/strategy/eb11344/strategy_english_web.pdf. (Accessed: 2nd July 2019)

196. Diez Roux, A. V. Complex systems thinking and current impasses in health disparities research. Am. J. Public Health 101, 1627-1634 (2011). 
197.Geng, E. H., Peiris, D. \& Kruk, M. E. Implementation science: Relevance in the real

$1278 \quad$ world without sacrificing rigor. PLoS Med. 14, e1002288 (2017).

1279 198. Huffman, M. D., Labarthe, D. R. \& Yusuf, S. Global cardiovascular research training for

1280 implementation science, health systems research, and health policy research. J. Am.

$1281 \quad$ Coll. Cardiol. 65, 1371-1372 (2015).

1282 199.Basu, S. \& Andrews, J. Complexity in mathematical models of public health policies: a 1283 guide for consumers of models. PLoS Med. 10, e1001540 (2013).

1284 200.Metcalf, C. J. E., Edmunds, W. J. \& Lessler, J. Six challenges in modelling for public 1285 health policy. Epidemics 10, 93-96 (2015).

1286 201.Carey, G. et al. Systems science and systems thinking for public health: a systematic 1287 review of the field. BMJ Open 5, e009002 (2015).

1288 202.Peters, D. H., Peters, M. A., Wickramasinghe, K., Osewe, P. L. \& Davidson, P. M. 1289 Asking the right question: implementation research to accelerate national non1290 communicable disease responses. BMJ 365, I1868 (2019).

203. Yapa, H. M. \& Bärnighausen, T. Implementation science in resource-poor countries and communities. Implement. Sci. 13, 154 (2018).

204.Pan American Health Organization \& Organisation for Economic Co-operation and Development. Applying Modeling to Improve Health and Economic Policy Decisions in the Americas The Case of Noncommunicable Diseases: The Case of Noncommunicable Diseases. (PAHO, 2015).

205.Collins, T. E. et al. Time to align: development cooperation for the prevention and control of non-communicable diseases. BMJ 366, I4499 (2019).

206. Kuruvilla, S. et al. Success factors for reducing maternal and child mortality. Bull. World Health Organ. 92, 533-44B (2014).

207.Wells, J. C. K. The capacity-load model of non-communicable disease risk: understanding the effects of child malnutrition, ethnicity and the social determinants of 1304 208. United Nations. Health. United Nations Sustainable Development Goals Available at: 
https://www.un.org/sustainabledevelopment/health/. (Accessed: 25th September 2019)

209. World Health Organization. Stronger Collaboration, Better Health: Global Action Plan for

1307 Healthy Lives and Well-being for All. (World Health Organization, 2019).

210. Krishna, B. et al. Tackling the health burden of air pollution in South Asia. BMJ 359, $1309 \quad j 5209(2017)$.

1310 211.Su, T.-C., Chen, S.-Y. \& Chan, C.-C. Progress of ambient air pollution and 1311 cardiovascular disease research in Asia. Prog. Cardiovasc. Dis. 53, 369-378 (2011).

1312 212.Chakraborty, D. \& Mondal, N. K. Hypertensive and toxicological health risk among 1313 women exposed to biomass smoke: A rural Indian scenario. Ecotoxicol. Environ. Saf. $1314 \quad$ 161, 706-714 (2018).

1315 213.India State-Level Disease Burden Initiative CVD Collaborators. The changing patterns 1316 of cardiovascular diseases and their risk factors in the states of India: the Global Burden 1317 of Disease Study 1990-2016. Lancet Glob Health 6, e1339-e1351 (2018).

1318 214. Yamamoto, S. S., Phalkey, R. \& Malik, A. A. A systematic review of air pollution as a 1319 risk factor for cardiovascular disease in South Asia: limited evidence from India and 1320 Pakistan. Int. J. Hyg. Environ. Health 217, 133-144 (2014).

1321 215.Jacob, A. M., Datta, M., Kumpatla, S., Selvaraj, P. \& Viswanthan, V. Prevalence of 1322 Diabetes Mellitus and Exposure to Suspended Particulate Matter. J Health Pollut 9, $1323190608(2019)$.

216.Pande, J. N. et al. Outdoor air pollution and emergency room visits at a hospital in Delhi. Indian J. Chest Dis. Allied Sci. 44, 13-19 (2002).

217.Shi, Y. et al. Long-term trends and spatial patterns of PM2.5-induced premature 1331 219.Dutta, A., Ray, M. R. \& Banerjee, A. Systemic inflammatory changes and increased 1332 oxidative stress in rural Indian women cooking with biomass fuels. Toxicol. Appl. 
Pharmacol. 261, 255-262 (2012).

220. Khafaie, M. A. et al. Particulate matter and markers of glycemic control and insulin resistance in type 2 diabetic patients: result from Wellcome Trust Genetic study. J. Expo. Sci. Environ. Epidemiol. 28, 328-336 (2018).

221. Khafaie, M. A. et al. Systemic inflammation (C-reactive protein) in type 2 diabetic patients is associated with ambient air pollution in Pune City, India. Diabetes Care 36, 625-630 (2013).

222. Balakrishnan, K. et al. Exposures to fine particulate matter (PM2.5) and birthweight in a rural-urban, mother-child cohort in Tamil Nadu, India. Environ. Res. 161, 524-531 (2018).

223.Epstein, M. B. et al. Household fuels, low birth weight, and neonatal death in India: the separate impacts of biomass, kerosene, and coal. Int. J. Hyg. Environ. Health 216, 523532 (2013).

224. Spears, D. et al. The association of early-life exposure to ambient PM2.5 and laterchildhood height-for-age in India: an observational study. Environ. Health 18, 62 (2019).

225.Pucher, J., Peng, Z., Mittal, N., Zhu, Y. \& Korattyswaroopam, N. Urban Transport Trends and Policies in China and India: Impacts of Rapid Economic Growth. Transp. Rev. 27, 379-410 (2007).

226. Groenewald, P. et al. Local-level mortality surveillance in resource-limited settings: a case study of Cape Town highlights disparities in health. Bull. World Health Organ. 88, 444-451 (2010).

227.Battersby, J. \& Crush, J. Africa's Urban Food Deserts. Urban Forum 25, 143-151 (2014).

228.Smit, W. et al. Making unhealthy places: The built environment and non-communicable diseases in Khayelitsha, Cape Town. Health Place 39, 196-203 (2016).

229. Hunter-Adams, J., Battersby, J. \& Oni, T. Food insecurity in relation to obesity in periurban Cape Town, South Africa: Implications for diet-related non-communicable disease. Appetite 137, 244-249 (2019). 
1361

1362

1363

1364

1365

1366

1367

1368

1369

1370

1371

1372

1373

1374

1375

1376

1377

1378

1379

1380

1381

1382

1383

1384

1385

1386

1387

1388

230. Alcohol. Key Facts. World Health Organization Available at: https://www.who.int/newsroom/fact-sheets/detail/alcohol. (Accessed: 26th September 2019)

231. World Health Organization. Global strategy to reduce the harmful use of alcohol. (World Health Organization, 2010).

232. World Health Organization. Global Status Report on Alcohol and Health 2018. (World Health Organization, 2018).

233. World Health Organization. Global Status Report on Alcohol and Health 2011. (World Health Organization, 2011).

234. Hawkins, B., Holden, C., Eckhardt, J. \& Lee, K. Reassessing policy paradigms: A comparison of the global tobacco and alcohol industries. Glob. Public Health 13, 1-19 (2018).

235. Global social responsibility initiatives. Worldwide Brewing Alliance (2007). Available at: https://worldwidebrewingalliance.org/docs/publications/WBA_Global_Social_Responsibil ity_Initiatives_2007.pdf. (Accessed: 26th September 2019)

236. Stenius, K. \& Babor, T. F. The alcohol industry and public interest science. Addiction 105, 191-198 (2010).

237.12th Conference of INEBRIA, 24th - 25th September 2015 Atlanta (Georgia). INEBRIA Available at: http://inebria.net/meetings-and-activities/conference/past/12th-conferenceof-inebria-24th-25th-september-2015-atlanta-georgia/. (Accessed: 26th September 2019)

238. Jernigan, D. H. Global alcohol producers, science, and policy: the case of the International Center for Alcohol Policies. Am. J. Public Health 102, 80-89 (2012).

239. Esser, M. B. \& Jernigan, D. H. Multinational Alcohol Market Development and Public Health: Diageo in India. Am. J. Public Health 105, 2220-2227 (2015).

240.Babor, T. F. \& Robaina, K. Public health, academic medicine, and the alcohol industry's corporate social responsibility activities. Am. J. Public Health 103, 206-214 (2013).

241. Our Plan W programme continues to be a success. Diageo Available at: https://www.diageo.com/en/news-and-media/features/our-plan-w-programme-continues- 
1390

\section{Conflict of interest}

1392 The authors declare no competing interests

1393

1394 


\section{Public health efforts}

Poverty, food insecurity
Infectious burden
Commercial determinants

Maternal factors
Under-nutrition
Short stature
Obesity
Infection
Psychosocial stress
Infant factors
Low birth weight
Wasting/stunting
Infection
HIGH
Capacity for
homeostasis
LOW

Child/adult phenotype

Lipogenic diet

Sedentary behaviour

Smoking

Obesity

Inflammation

Pyschosocial stress
Blood pressure Glycemic control Arterial health

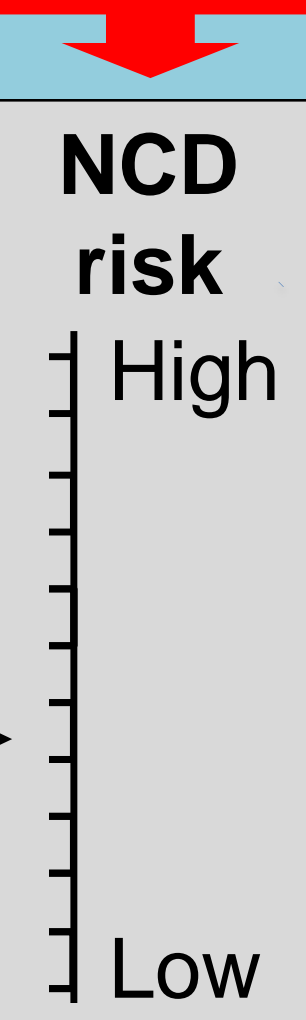

